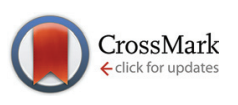

Cite this: Dalton Trans., 2016, 45, 5640

Received 27th January 2016, Accepted 16th February 2016 DOI: $10.1039 / c 6 d t 00384 b$ www.rsc.org/dalton

\section{The photochemistry of mono- and dinuclear cyclometalated bis(tridentate)ruthenium(ı) complexes: dual excited state deactivation and dual emission $\dagger$}

\begin{abstract}
Christoph Kreitner ${ }^{a, b}$ and Katja Heinze*a
The synthesis and characterization of a series of weakly emissive mononuclear cyclometalated $[R u(d p b-R)$ (tpy) $]^{+}$complexes with functional groups $\mathrm{R}$ of varying electron-donating characters at the dpb ligand are described (dpbH = 1,3-di(2-pyridyl)benzene, tpy $=2,2^{\prime} ; 6^{\prime}, 2^{\prime \prime}$-terpyridine, $\mathbf{1}^{+}: \mathrm{R}=\mathrm{NHCOMe}, \mathbf{2}^{+}: \mathrm{R}=\mathrm{NH}_{2}$, $3^{+}: \mathrm{R}=\mathrm{COOEt}, \mathbf{4}^{+}: \mathrm{R}=\mathrm{COOH}$ ). Steady-state emission spectroscopy in the temperature range between $298 \mathrm{~K}$ and $77 \mathrm{~K}$ revealed a previously unrecognized excited state deactivation pathway via low-lying triplet ligand-to-ligand ( $\left.{ }^{3} \mathrm{LL} \mathrm{L}^{\prime} \mathrm{C} T\right)$ charge transfer states in addition to the well-known pathway via ${ }^{3} \mathrm{MC}$ states. Thermal activation barriers for depopulation of the emissive metal-to-ligand charge transfer $\left({ }^{3} \mathrm{MLCT}\right)$ states via the ${ }^{3} \mathrm{MC}$ (metal-centered) and ${ }^{3} \mathrm{LL}$ 'CT states were determined experimentally for complexes $\mathbf{1}^{+}$ and $3^{+}$. The experimental results were further corroborated by calculating the respective ${ }^{3} \mathrm{MLCT}-{ }^{3} \mathrm{LL} \mathrm{L}^{\prime} \mathrm{CT}$ and ${ }^{3} \mathrm{MLCT}-{ }^{3} \mathrm{MC}$ transition states and their energies with density functional theoretical methods. The $\mathrm{R}$ substituent modifies the energy difference between the ${ }^{3} \mathrm{MLCT}$ and ${ }^{3} \mathrm{LL}$ 'CT states and the corresponding activation barrier but leaves the analogous ${ }^{3} \mathrm{MLCT} /{ }^{3} \mathrm{MC}$ energetics essentially untouched. Additionally, the dinuclear complex $[(\mathrm{tpy}) \mathrm{Ru}(\mathrm{dpb}-\mathrm{NHCO}-\mathrm{dpb}) \mathrm{Ru}(\mathrm{tpy})]^{2+}, 6^{2+}$, containing a biscyclometalating bridge was devised. Despite the asymmetric nature induced by the amide bridge, the mixed-valent cation $6^{3+}$ is ascribed to Robin-Day class II with a broad and intense intervalence charge-transfer (IVCT) absorption $\left(\lambda_{\max }=1165 \mathrm{~nm}\right)$. Upon optical excitation, the Ru" $/ \mathrm{Ru}$ " complex $6^{2+}$ exhibits dual emission in liquid solution from two independently emitting ${ }^{3} \mathrm{MLCT}$ states localized at the two remote $[\mathrm{Ru}(\mathrm{tpy})]$ fragments. No equilibration via Dexter energy transfer is possible due to their large distance and short excited state lifetimes.
\end{abstract}

\section{Introduction}

Polypyridine complexes of ruthenium(II) have been known and studied for the past sixty years. ${ }^{1,2}$ Although the fundamentals of their photo- and electrochemical properties are well understood, ${ }^{3-7}$ research efforts have not diminished over the last few years mainly due to a widespread potential for applications for this class of metal complexes. These vary from photoredox catalysis, ${ }^{8-12}$ over light sensitization in dye-sensitized solar cells, ${ }^{13}$ and sensing applications in biological ${ }^{14,15}$ and chemical ${ }^{16}$ contexts to optoelectronics. ${ }^{17}$

\footnotetext{
${ }^{a}$ Institute of Inorganic and Analytical Chemistry, Johannes Gutenberg University, Duesbergweg 10-14, D-55128 Mainz, Germany. E-mail: katja.heinze@uni-mainz.de ${ }^{b}$ Graduate School Materials Science in Mainz, Staudingerweg 9, D-55128 Mainz, Germany

$\dagger$ Electronic supplementary information (ESI) available. See DOI: 10.1039/ c6dt00384b
}

The prototype of this class of complexes is $\left[\mathrm{Ru}(\mathrm{bpy})_{3}\right]^{2+}$ (bpy $=2,2$-bipyridine), whose photophysical properties have been extensively studied and are well understood. Under visible light irradiation, excitation into a singlet metal-toligand charge transfer $\left({ }^{1}\right.$ MLCT $)$ state occurs $\left(\lambda_{\max }=452 \mathrm{~nm}\right.$, $\left.\varepsilon_{\text {max }}=14.6 \mathrm{M}^{-1} \mathrm{~cm}^{-1}\right) .1,3$ This state undergoes rapid and quantitative intersystem crossing onto the triplet hypersurface ${ }^{18,19}$ populating a long-lived ${ }^{3}$ MLCT state that is phosphorescent at room temperature $\left(\lambda_{\mathrm{em}}=621 \mathrm{~nm}, \phi=0.095, \tau=855 \mathrm{~ns}\right.$ in $\mathrm{MeCN}) .{ }^{20,21}$ Upon cooling, both, emission quantum yield and excited state lifetime, increase drastically. Using lifetime measurements at varying temperatures, T. J. Meyer and coworkers showed that this temperature dependence is due to a thermally accessible $\mathrm{d}-\mathrm{d}$ excited state (metal centered, ${ }^{3} \mathrm{MC}$ ) that rapidly undergoes vibrational relaxation into the ground state $\left({ }^{1} \mathrm{GS}\right) .{ }^{20,22}$ Additionally, this excited state is dissociative in nature and enables $\left[\mathrm{Ru}(\mathrm{bpy})_{3}\right]^{2+}$ to undergo photosubstitution reactions. ${ }^{20,22,23}$ 
To suppress these reactions and also to circumvent the chiral nature of $\left[\mathrm{Ru}(\mathrm{bpy})_{3}\right]^{2+}$ stronger chelating, tridentate ligands such as tpy (tpy $=2,2^{\prime} ; 6^{\prime}, 2^{\prime \prime}$-terpyridine) were introduced in bis(tridentate)ruthenium(II) complexes. ${ }^{5,24}$ Their meridional coordination geometry ${ }^{25}$ allows the functionalization of the ligand periphery without resulting in stereoisomers. A major drawback of these complexes compared to their bpy counterparts is the almost complete lack of emission at room temperature $\left(\phi=5 \times 10^{-6}\right) \cdot{ }^{5,26}$ Due to the weaker ligand field caused by the smaller bite angle of the terpyridine ligand $\left(\mathrm{N}-\mathrm{Ru}-\mathrm{N} \approx 79^{\circ}\right)$, the emissive ${ }^{3}$ MLCT states of $\left[\mathrm{Ru}(\mathrm{tpy})_{2}\right]^{2+}$ are very efficiently depopulated via low-lying ${ }^{3} \mathrm{MC}$ states. ${ }^{24}$ Upon cooling, thermal depopulation of the emissive state is retarded yielding bright luminescence at $77 \mathrm{~K}\left(\lambda_{\mathrm{em}}=599 \mathrm{~nm}, \phi=0.48\right.$, $\tau=110 \mu \mathrm{s}$ in $\mathrm{MeOH} / \mathrm{EtOH}) .{ }^{27}$

Various attempts have been made to regain room temperature luminescence from bis(tridentate)ruthenium(II) complexes. By introducing an electron-donating functional group on one of the terpyridine ligands, the energy of the ${ }^{3} \mathrm{MC}$ state is increased with respect to the ${ }^{3}$ MLCT state energy rather selectively. ${ }^{5}$ Similarly, electron-accepting functionalities lower the ${ }^{3}$ MLCT state energy. ${ }^{5}$ Combining these two approaches in a push-pull system, the activation barrier for depopulation of the emissive ${ }^{3}$ MLCT state is increased. As a result, room temperature quantum yields of up to 0.003 and excited state lifetimes of $50 \mathrm{~ns}$ are achieved. ${ }^{5,28-31}$ Since the coordination mode of the tpy ligand with five-membered chelate rings only allows for rather constrained geometries around the metal center with small bite angles, several research groups focussed on expanding the ligand backbone to increase the overlap between the ruthenium d orbitals of the $e_{g}$ set and the nitrogen lone pairs. This yields an enlarged ligand field splitting and thus makes ${ }^{3} \mathrm{MC}$ states as deactivation pathway thermally less accessible at room temperature. ${ }^{32-35}$ Following this concept, bis(tridentate)ruthenium(II) complexes were synthesized with optical properties comparable to those of $\left[\mathrm{Ru}(\mathrm{bpy})_{3}\right]^{2+}(\phi=0.30, \tau=3.3 \mu \mathrm{s}) .{ }^{33}$

In a very similar approach, by introduction of very strong $\sigma$-donors in the coordination sphere, the ligand field splitting can be increased compared to $\left[\mathrm{Ru}(\mathrm{tpy})_{2}\right]^{2+}$. Conceptually, this was shown by Berlinguette and Schubert using N-heterocyclic carbene containing tridentate ligands $\left(\mathrm{C}^{\wedge} \mathrm{N}^{\wedge} \mathrm{C}\right.$ coordination mode) with quantum yields of 0.11 and excited state lifetimes of up to $8 \mathrm{\mu s}^{36}$ Disappointingly, attempts using 1,3-di(2pyridyl)benzene $(\mathrm{dpbH})$, deprotonated in the 2-position of the central benzene ring, as a strong cyclometalating $\sigma$-donor ligand in conjunction with tpy as a $\pi$-accepting ligand $\left([\mathrm{Ru}(\mathrm{dpb})(\mathrm{tpy})]^{+}\right)$, gave only very weakly emissive complexes. ${ }^{30,37-40}$ This was originally ascribed to a very small activation barrier for thermal depopulation of the emissive ${ }^{3}$ MLCT state via low-lying ${ }^{3} \mathrm{MC}$ states since the cyclometalation at the central position of the dpb ligand merely shifts one of the ${ }^{3} \mathrm{MC}$ states to a higher energy. ${ }^{30}$ Recently, we have suggested that the introduction of a very strong push-pull arrangement across the metal center additionally gives rise to low-lying triplet ligand-to-ligand charge transfer $\left({ }^{3} \mathrm{LL} \mathrm{LT}^{\prime} \mathrm{C}\right)$ states. ${ }^{40}$ Since the involved ligands are orthogonal to one another in the meridional coordination geometry, so are the spin-carrying orbitals. Hence, emission from such ${ }^{3}$ LL'CT states is symmetry-forbidden and leads to efficient radiationless deactivation of the excited state.

To further study this phenomenon and to elaborate a general view, the work presented herein devised four cyclometalated ruthenium complexes $[\mathrm{Ru}(\mathrm{dpb}-\mathrm{R})(\mathrm{tpy})]^{+}$with varying substituents at the 5-position of the dpb ligand ( $\mathrm{R}=$ NHCOMe, $\mathbf{1}^{+} ; \mathrm{R}=\mathrm{NH}_{2}, 2^{+} ; \mathrm{R}=\mathrm{COOEt}, 3^{+} ; \mathrm{R}=\mathrm{COOH}, \mathbf{4}^{+}$). Using these, it is possible to systematically study the impact of varying pushpull strengths across the metal center on the ground and excited state properties of these cyclometalated complexes. By employing steady-state emission spectroscopy, we demonstrate that the occurrence of low-energy ${ }^{3} \mathrm{LL}$ 'CT states is a common theme in cyclometalated bis(tridentate)ruthenium complexes providing a second excited state deactivation pathway in addition to the well-known pathway mediated by ${ }^{3} \mathrm{MC}$ states.

Additionally, the presence of free amino and carboxylic acid groups allows the straightforward formation of a dinuclear complex with an amide-linked biscyclometalating bridging ligand $\left([(\text { tpy }) \mathrm{Ru}(\mathrm{dpb}-\mathrm{NHCO}-\mathrm{dpb}) \mathrm{Ru}(\mathrm{tpy})]^{2+}\left(6^{2+}\right)\right.$ that we synthesized and studied as well. Dinuclear bisruthenium complexes received wide interest since the discovery of the mixedvalent Creutz-Taube ion, $\left[\left(\mathrm{NH}_{3}\right)_{5} \mathrm{Ru}(\mu-\mathrm{pz}) \mathrm{Ru}\left(\mathrm{NH}_{3}\right)_{5}\right]^{5+}(\mathrm{pz}=$ pyrazine). ${ }^{41-43}$ The ruthenium oxidation states within this mixed-valent complex cannot be assigned unambiguously. Depending on the spectroscopic method either $2+/ 3+$ or $2.5+/$ $2.5+$ is obtained. ${ }^{4-47}$ Dinuclear mixed-valent complexes are assigned to three different groups based on Robin's and Day's classification. ${ }^{48}$ Systems with entirely localized valences and no electronic coupling between the redox centers in the mixedvalent state are referred to as Robin-Day class I, and systems with entirely delocalized valences are assigned as class III. Class II describes valence-localized complexes with measurable electronic interactions between the redox sites. The theoretical basis for an accurate physicochemical treatment of Robin-Day class II complexes was laid by Hush ${ }^{49-51}$ describing the photochemical electron transfer occurring between the donor and acceptor sites $\left[\mathbf{M}^{n+}-\mathbf{M}^{(n+1)+} \rightarrow \mathbf{M}^{(n+1)+}-\mathbf{M}^{n+}\right]$. This process yields an intervalence charge transfer (IVCT) absorption that is typically observed in the Near Infrared (NIR) region of the electronic absorption spectrum of a Robin-Day class II compound. According to Marcus-Hush theory, this IVCT band is correlated with the electronic coupling parameter $V_{\mathrm{ab}}$ between the redox centers calculated as: $V_{\mathrm{ab}}=2.06 \times 10^{-2}$ $\left.\tilde{\nu}_{\max } \cdot \varepsilon_{\max } \cdot \tilde{\nu}_{1 / 2}\right)^{1 / 2} r^{-1}$ with the absorption maximum $\tilde{\nu}_{\max }$ in $\mathrm{cm}^{-1}$, the extinction coefficient $\varepsilon_{\max }$ at $\tilde{\nu}_{\max }$ in $\mathrm{M}^{-1} \mathrm{~cm}^{-1}$, the full width at half maximum $\tilde{\nu}_{1 / 2}$ in $\mathrm{cm}^{-1}$ and the donoracceptor distance $r$ in $\AA^{47,52}$

Several amide-bridged dinuclear bis(terpyridine)ruthenium(II) complexes and their mixed-valent counterparts have been described in the literature. ${ }^{53-55}$ While the back-to-back linked $(n=0)$ or phenylene-extended $(n=1-2)$ dinuclear bis(terpyridine)ruthenium(II) complexes [(ttpy)Ru(tpy-(1,4- $\left.\mathrm{C}_{6} \mathrm{H}_{4}\right)_{n}$-tpy)Ru$($ ttpy $)]^{4+}$ (ttpy $=4^{\prime}$-tolylterpyridine, 1,4- $\mathrm{C}_{6} \mathrm{H}_{4}=$ para-phenylene) 
exhibit electronic coupling of the metal centers in the mixedvalent state to a small extent $\left(n=0: V_{\mathrm{ab}}=0.047 \mathrm{eV}, n=1: V_{\mathrm{ab}}=\right.$ $\left.0.030 \mathrm{eV}, n=2: V_{\mathrm{ab}}=0.022 \mathrm{eV}\right),{ }^{56,57}$ the introduction of an amide bridge seems to reduce the molecular and redox-chemical symmetry enough to prevent the electronic interactions entirely. ${ }^{54,55}$ In the cyclometalated analogue of the dinuclear back-to-back linked bis(terpyridine)ruthenium complex, [(ttpy) $\mathrm{Ru}(\mathrm{dpb}-\mathrm{dpb}) \mathrm{Ru}(\mathrm{tpy})]^{2+}$, on the other hand, the metal-metal interaction is increased to $V_{\mathrm{ab}}=0.127 \mathrm{eV} .^{58,59}$ This increase was attributed to an energy shift of the bridge's frontier orbitals to better match those of the metal centers. ${ }^{59,60}$ In this work, we study to what extent the insertion of an NHCO group into the bridge reduces the electronic coupling between the metal centers in the mixed-valent state $6^{3+}$ and the interaction of the triplet excited states of $6^{2+}$.

\section{Results and discussion}

\section{Synthesis and characterization of mono- and dinuclear complexes}

The synthesis (Scheme 1) of the target mononuclear complexes was carried out following a previously described synthetic route starting from $\mathrm{RuCl}_{3}$ (tpy). ${ }^{40,58}$ In the first step, this precursor is activated by chloride abstraction using silver tetrafluoroborate. The resulting solvent complex intermediate was subsequently treated with the respective dipyridylbenzene ligand $\mathbf{L} 1$ or $\mathbf{L} 2^{40}$ to give the amide or ester substituted $[\mathrm{Ru}(\mathrm{dpb}-\mathrm{R})(\mathrm{tpy})]^{+}$complexes $\mathbf{1}\left(\mathrm{PF}_{6}\right)$ and $\mathbf{3}\left(\mathrm{PF}_{6}\right)$ in good yields. Cleavage of the functional groups for the liberation of free amine or carboxylic acid was achieved in aqueous methanolic solutions using sodium hydroxide as a base and hydrazine as a reductant to prevent oxidative decomposition. This hydrolysis protocol gives comparable yields to the hydrolysis of structurally related ruthenium complexes by trimethylamine employed by Berlinguette and coworkers. ${ }^{61}$

In order to accomplish the coupling reaction between the free acid and the amine moieties of $2^{+}$and $4^{+}$to the dinuclear complex $6^{2+}$, activation of the acid component is necessary. This was achieved similarly to a previously employed technique using $N$-hydroxybenzotriazole (HOBt) and $N, N^{\prime}$-diisopropylcarbodiimide (DIC). ${ }^{55,62}$ Compared to the amide coupling reaction between bis(terpyridine)ruthenium(II) amino acid derivatives described previously, ${ }^{54,55}$ the coupling had to be performed at elevated temperatures, possibly attributed to the reduced acidity of the amino functionality and relatively weak nucleophilicity of the OBt ester compared to other active esters.

All complexes were characterized using 1D- and 2D-NMR techniques (ESI, Fig. S1-S14†) as well as ESI and highresolution ESI mass spectrometry (ESI, Fig. S15†). The purity of all compounds under study was confirmed by elemental analyses. Successful amide cleavage $\left(1\left(\mathrm{PF}_{6}\right) \rightarrow 2\left(\mathrm{PF}_{6}\right)\right)$ is proven by the disappearance of the $\mathrm{NH}(8.62 \mathrm{ppm})$ and $\mathrm{CH}_{3}$ $(2.23 \mathrm{ppm})$ resonances in the proton NMR spectrum of $2\left(\mathrm{PF}_{6}\right)$. Simultaneously, a new significantly broadened resonance
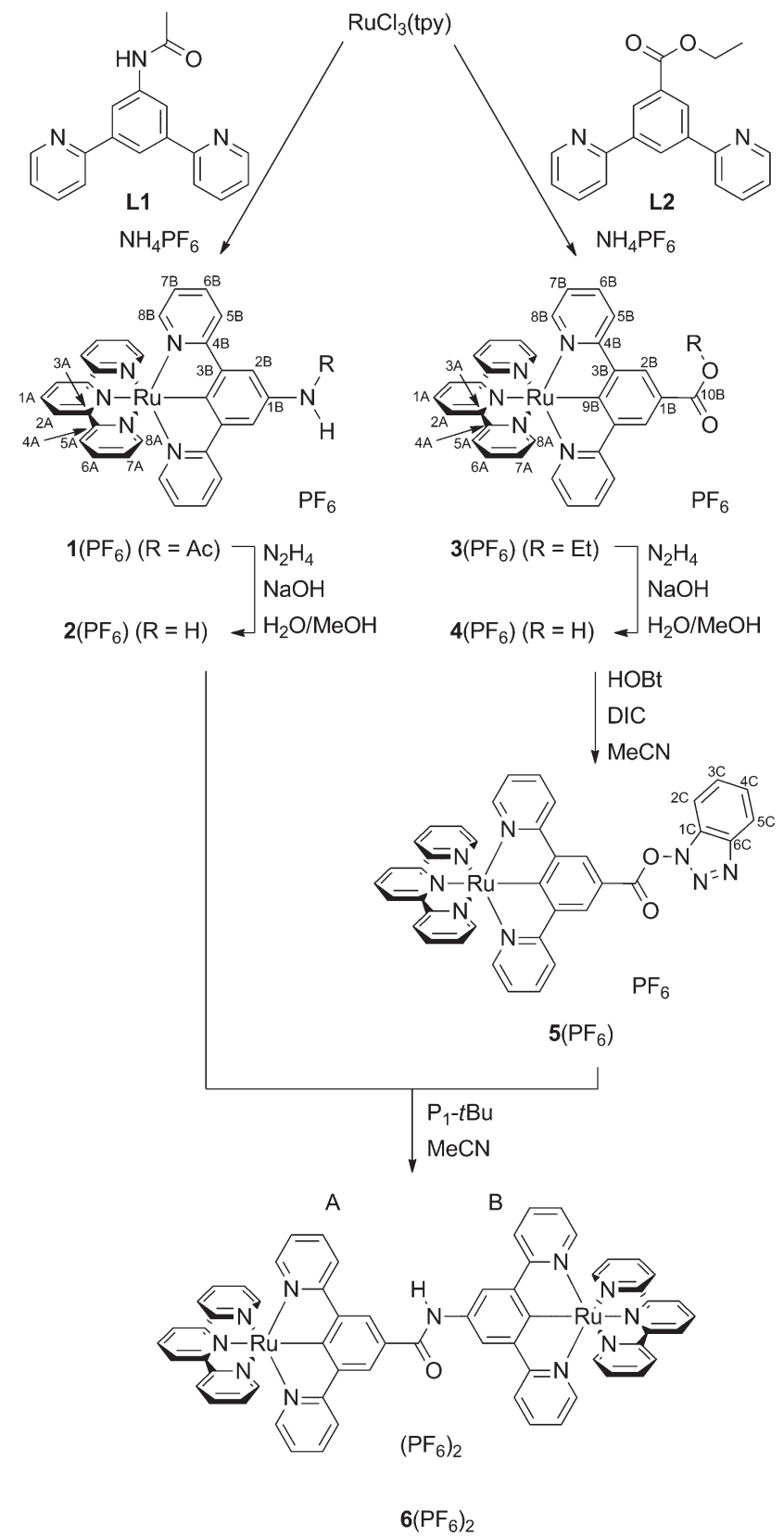

Scheme 1 Synthesis of the mononuclear complexes $1\left(P_{6}\right)-5\left(P F_{6}\right)$ and the dinuclear complex $6\left(\mathrm{PF}_{6}\right)_{2}$ from $\mathrm{RuCl}_{3}(\mathrm{tpy})$. Atom numbering for NMR assignment is included.

appears at $4.24 \mathrm{ppm}$ indicating the presence of a free amino group. Similarly, ester saponification $\left(3\left(\mathrm{PF}_{6}\right) \rightarrow \mathbf{4}\left(\mathrm{PF}_{6}\right)\right)$ yields a loss of the characteristic $\mathrm{CH}_{2}$ and $\mathrm{CH}_{3}$ proton resonances of the ethyl group while essentially leaving the aromatic region of the ${ }^{1} \mathrm{H}$ NMR spectrum unaffected. For the hydroxybenzotriazole ester $\mathbf{5}\left(\mathrm{PF}_{6}\right)$, the resonances of the dipyridylbenzene ligand, predominantly those in the $2 \mathrm{~B}$-position, are shifted to a lower field. This is in agreement with the formation of a more electron-deficient species that is activated towards nucleophilic attack. 
Interestingly, the functional group attached to the $\mathrm{dpb}$ ligand strongly affects the ${ }^{13} \mathrm{C}$ chemical shift of the coordinating carbon atom. While this resonance is found at $239.5 \mathrm{ppm}$ in complex $\mathbf{5}\left(\mathrm{PF}_{6}\right)$ with the strongly electron-withdrawing COOBt substituent, it is shifted upfield to $233 \mathrm{ppm}$ in complexes $3\left(\mathrm{PF}_{6}\right)$ and $4\left(\mathrm{PF}_{6}\right)$ with COOEt and $\mathrm{COOH}$ functional groups. In the $\mathrm{N}$-substituted complexes, it is found at even lower chemical shifts, namely at $217.2 \mathrm{ppm}$ for $\mathbf{1}\left(\mathrm{PF}_{6}\right)$ and at $208.9 \mathrm{ppm}$ for $2\left(\mathrm{PF}_{6}\right)$. This also reflects the electrochemistry at the ruthenium center (vide infra).

Evidence for the success of the amide coupling between $2\left(\mathrm{PF}_{6}\right)$ and $\mathbf{5}\left(\mathrm{PF}_{6}\right)$ is gained from the ${ }^{1} \mathrm{H}$ NMR spectrum of $6\left(\mathrm{PF}_{6}\right)_{2}$. The proton resonance at low field $(9.63 \mathrm{ppm})$ with an integral of a single proton indicates the presence of an amide bridge. Additionally, all aromatic signal sets occur four times in a $1: 1: 1: 1$ ratio. Although the resonances of the two terpyridine ligands are distinguishable due to the different substituents at the remote dpb ligands, an unambiguous assignment to one of the two capping ligands is impossible. The ESI mass spectrum, which shows the required peaks at $\mathrm{m} / \mathrm{z}=586.6$ for $6^{2+}$ and at 1318.3 for $\mathbf{6}\left(\mathrm{PF}_{6}\right)^{+}$with isotope patterns characteristic for a complex containing two ruthenium atoms, gives additional support to the successful formation of the dinuclear complex.

IR spectroscopy further confirms all structures under study (ESI, Fig. S16 $\dagger$ ). All the complexes exhibit an intense IR absorption at $843 \mathrm{~cm}^{-1}$ arising from P-F stretching vibrations within the $\mathrm{PF}_{6}{ }^{-}$counterion. The amino-substituted complex $2^{+}$shows a broad, intense absorption at $3420 \mathrm{~cm}^{-1}$ arising from $\mathrm{N}-\mathrm{H}$ stretching vibrations of the $\mathrm{NH}_{2}$ group. The amide containing complexes $\mathbf{1}^{+}$and $\mathbf{6}^{2+}$ exhibit a broad absorption band at around $3220-3230 \mathrm{~cm}^{-1}$ ascribed to the $\mathrm{N}-\mathrm{H}$ stretch along with intense $\mathrm{C}=\mathrm{O}$ vibrations at $1650 \mathrm{~cm}^{-1}$ and $1635 \mathrm{~cm}^{-1}$, respectively. Similar $\mathrm{C}=\mathrm{O}$ vibrations are observed for the carboxy-substituted complexes $3^{+}$and $\mathbf{4}^{+}$, with that of the ester occurring at $1695 \mathrm{~cm}^{-1}$ and that of the carboxylic acid at $1665 \mathrm{~cm}^{-1}$. Additionally, the carboxylic acid $4^{+}$exhibits a broad absorption at $3440 \mathrm{~cm}^{-1}$ (O-H stretch) along with absorptions in the range between 3000 and $2300 \mathrm{~cm}^{-1}$ typical for carboxylic acids.

\section{Electrochemical properties of complexes $1\left(\mathrm{PF}_{6}\right)-4\left(\mathrm{PF}_{6}\right)$ and $6\left(\mathrm{PF}_{6}\right)_{2}$}

The cyclic voltammograms of the complexes $\mathbf{1}\left(\mathrm{PF}_{6}\right)-\mathbf{4}\left(\mathrm{PF}_{6}\right)$ and 6 $\left(\mathrm{PF}_{6}\right)_{2}$ are depicted in Fig. 1 and the respective electrochemical data are summarized in Table 1. For all mononuclear complexes, $\mathbf{1}\left(\mathrm{PF}_{6}\right)-\mathbf{4}\left(\mathrm{PF}_{6}\right)$, a single reversible oxidation is observed in the range between $-0.2 \mathrm{~V}$ and $0.28 \mathrm{~V}$ versus the ferrocene/ ferrocenium redox couple. It is ascribed to the $\mathrm{Ru}^{\mathrm{II}} / \mathrm{Ru}^{\mathrm{III}}$ couple. The electrochemical data of the ethyl ester-substituted complex $3\left(\mathrm{PF}_{6}\right)$ agree well with those of the methyl ester reported in the literature. ${ }^{30}$ With increasing electron-accepting properties of the respective substituent, this redox process is shifted to higher potentials by almost $500 \mathrm{mV}$. This suggests a strong contribution of the dpb ligand to the highest occupied molecular orbital (HOMO) of these complexes.

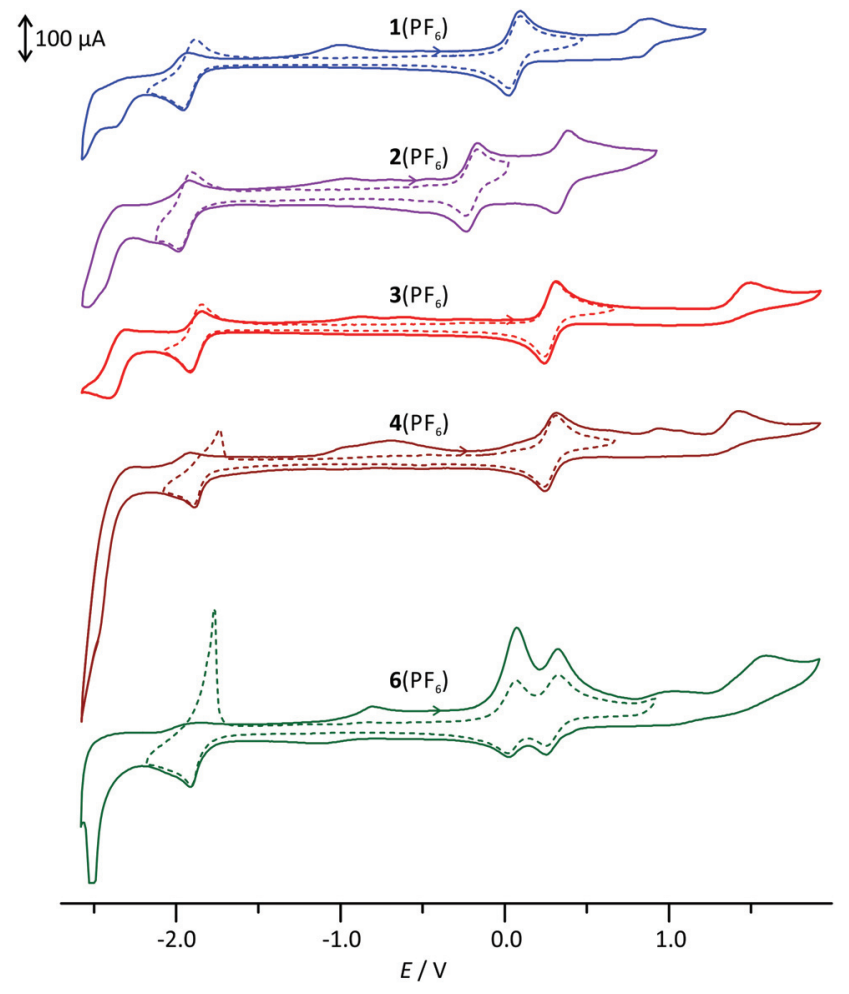

Fig. 1 Cyclic voltammograms of $1\left(\mathrm{PF}_{6}\right)-4\left(\mathrm{PF}_{6}\right)$ and $6\left(\mathrm{PF}_{6}\right)_{2}$ in $\mathrm{MeCN}$ with $0.1 \mathrm{~mol} \mathrm{l}^{-1}\left[n \mathrm{Bu}_{4} \mathrm{~N}\right]\left[\mathrm{PF}_{6}\right]$ as the supporting electrolyte.

Density functional theory (DFT) calculations further illustrate and enlighten these experimental findings. We have shown previously ${ }^{40}$ that the B3LYP functional ${ }^{63}$ along with a split-valence double- $\xi$ basis set and polarization functions on all non-hydrogen atoms (def2-SV(P) $)^{64-66}$ provides reasonable access to the electronic properties of the numerous charge transfer states of the complexes under study when combined with the ZORA relativistic approximation ${ }^{67}$ and a continuum solvent model (COSMO). ${ }^{68}$

Indeed, DFT calculations for the singlet ground states of the respective cationic complexes nicely reproduce the dependence of the energy of the HOMO from the substitution pattern (Fig. 2). Additionally, the shape of the HOMO parallels that of the doublet spin density of the $\mathrm{Ru}^{\mathrm{III}}$ complexes $\mathbf{1}^{2+}-\mathbf{4}^{2+}$ (ESI, Table S2 $\dagger$ ) supporting the fact that oxidation occurs on both the metal site and the dpb ligand. At substantially higher potentials, a second, irreversible oxidation is observed. It is again assigned to a mixed metal/dpb ligand oxidation yielding $\mathrm{a}[\mathrm{Ru}(\mathrm{dpb})]^{3+}$ state as suggested previously by DFT calculations for analogous complexes. ${ }^{40}$ The dependence of this second oxidation from the substitution pattern is even more pronounced so that its potential ranges from $0.35 \mathrm{~V}$ for amine-substituted $2\left(\mathrm{PF}_{6}\right)$ to $1.49 \mathrm{~V}$ for ester-substituted $3\left(\mathrm{PF}_{6}\right)$.

All four mononuclear complexes exhibit one reversible and several unresolved irreversible reductions. According to DFT calculations on the ground and the one-electron reduced states of $\mathbf{1}^{+}-\mathbf{4}^{+}\left(\mathbf{1}^{0}-\mathbf{4}^{0}\right)$, the first reduction is ascribed to a 
Table 1 Electrochemical data of complexes $1\left(\mathrm{PF}_{6}\right)-4\left(\mathrm{PF}_{6}\right)$ and $6\left(\mathrm{PF}_{6}\right)_{2}$, obtained from $0.1 \mathrm{~mol} \mathrm{l}^{-1}\left[n \mathrm{nu}_{4} \mathrm{~N}\right]\left[\mathrm{PF}_{6}\right]$ containing acetonitrile solution. Potentials are referenced against the $\mathrm{FcH} / \mathrm{FcH}^{+}$couple. Energy differences $E_{\mathrm{HO} O}-E_{\mathrm{LUMO}}$ are obtained from DFT calculations (see the MO diagram in Fig. 2)

\begin{tabular}{|c|c|c|c|c|c|c|c|}
\hline & $E_{\mathrm{ox}, 1} / \mathrm{V}$ & $E_{\mathrm{ox}, 2} / \mathrm{V}$ & $E_{\mathrm{ox}, 3} / \mathrm{V}$ & $E_{\text {red, } 1} / \mathrm{V}$ & $\begin{array}{l}E_{\text {red,2 }} / \\
\mathrm{V}\end{array}$ & $\begin{array}{l}E_{\mathrm{ox}, 1}- \\
E_{\mathrm{red}, 1} / \mathrm{V}\end{array}$ & $\begin{array}{l}E_{\mathrm{LUMO}}- \\
E_{\text {HOMO }} / \mathrm{eV}\end{array}$ \\
\hline $\mathbf{1}\left(\mathrm{PF}_{6}\right)$ & $\begin{array}{l}0.06([\mathrm{Ru}-\mathrm{dpb}] / \\
\left.[\mathrm{Ru}-\mathrm{dpb}]^{+}\right)^{a}\end{array}$ & $\begin{array}{l}0.86\left([\mathrm{Ru}-\mathrm{dpb}]^{+} / /\right. \\
\left.[\mathrm{Ru}-\mathrm{dpb}]^{2+}\right)^{b}\end{array}$ & - & $-1.93(\text { tpy/tpy })^{-}$ & $-2.54^{c}$ & 1.99 & 2.72 \\
\hline $2\left(\mathrm{PF}_{6}\right)$ & $\begin{array}{l}-0.20([\mathrm{Ru}-\mathrm{dpb}] / \\
\left.[\mathrm{Ru}-\mathrm{dpb}]^{+}\right)^{a}\end{array}$ & $\begin{array}{l}0.35\left([\mathrm{Ru}-\mathrm{dpb}]^{+} / /\right. \\
\left.[\mathrm{Ru}-\mathrm{dpb}]^{2+}\right)^{a}\end{array}$ & - & $-1.95(\text { tpy/tpy })^{a}$ & $-2.48^{c}$ & 1.75 & 2.48 \\
\hline $3\left(\mathrm{PF}_{6}\right)$ & $\begin{array}{l}0.28([\mathrm{Ru}-\mathrm{dpb}] / \\
\left.[\mathrm{Ru}-\mathrm{dpb}]^{+}\right)^{a}\end{array}$ & $\begin{array}{l}1.49\left([\mathrm{Ru}-\mathrm{dpb}]^{+} /\right. \\
\left.[\mathrm{Ru}-\mathrm{dpb}]^{2+}\right)^{b}\end{array}$ & - & $-1.87\left(\mathrm{tpy} / \mathrm{tpy}^{-}\right)^{a}$ & $-2.40^{c}$ & 2.15 & 2.98 \\
\hline $6\left(\mathrm{PF}_{6}\right)_{2}$ & $\begin{array}{l}0.05([\mathrm{Ru}-\mathrm{Ru}] / \\
\left.[\mathrm{Ru}-\mathrm{Ru}]^{+}\right)^{a}\end{array}$ & $\begin{array}{l}0.29\left([\mathrm{Ru}-\mathrm{Ru}]^{+} /\right. \\
\left.[\mathrm{Ru}-\mathrm{Ru}]^{2+}\right)^{a}\end{array}$ & $\begin{array}{l}1.58\left([\mathrm{Ru}-\mathrm{Ru}]^{2+} /\right. \\
\left.[\mathrm{Ru}-\mathrm{Ru}]^{3+}\right)^{b}\end{array}$ & $-1.85\left(2 \mathrm{e}^{-}, \mathrm{tpy} \mathrm{tpy}^{-}\right)^{a}$ & $-2.51^{c}$ & 1.90 & 2.64 \\
\hline
\end{tabular}

${ }^{a}$ Reversible, $E_{1 / 2}$ given. ${ }^{b}$ Irreversible, anodic peak potential given. ${ }^{c}$ Irreversible, cathodic peak potential given.

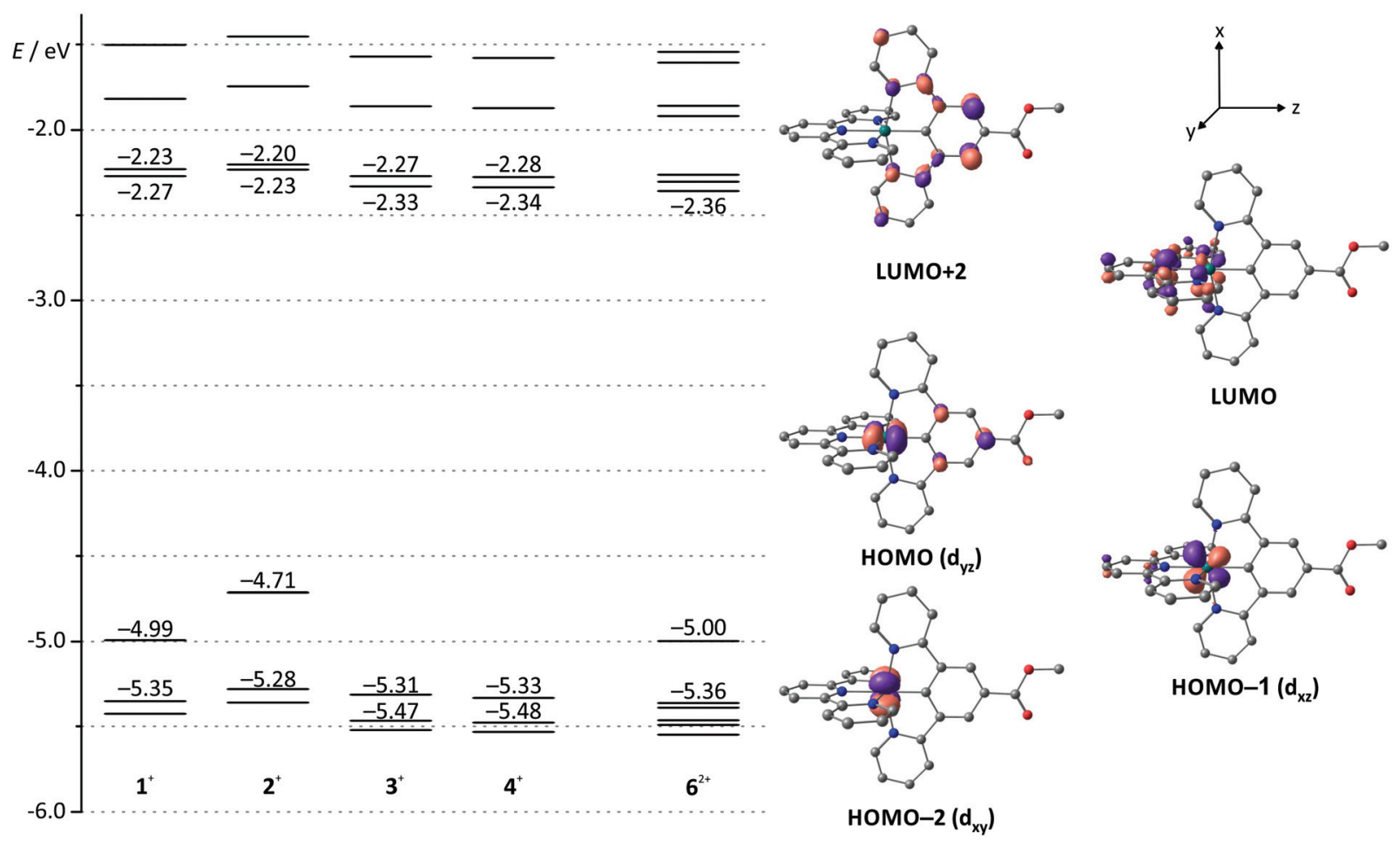

Fig. 2 Molecular orbital energy diagram of complexes $1\left(\mathrm{PF}_{6}\right)-4\left(\mathrm{PF}_{6}\right)$ and $6\left(\mathrm{PF}_{6}\right)_{2}$ obtained from DFT calculations (B3LYP, def2-SV(P), COSMO (acetonitrile), ZORA). Frontier orbitals are depicted exemplary for $3\left(\mathrm{PF}_{6}\right)$ since the shape of the respective orbital varies only marginally among the mononuclear complexes (see also ESI, Table S1†). Hydrogen atoms are omitted for clarity.

tpy-centered reduction (ESI, Table S2 $\dagger$ ). The $\mathrm{COOH}$-substituted complex $4\left(\mathrm{PF}_{6}\right)$ shows a stripping peak upon reoxidation following the first reduction. We ascribe this phenomenon to precipitation of the neutral complex moiety $\left[\mathrm{Ru}^{\mathrm{II}}\left(\mathrm{dpb}^{-}-\mathrm{COOH}\right)\right.$ $\left(\right.$ tpy $\left.\left.^{-}\right)\right] \mathbf{4}^{0}$ on the electrode surface and subsequent redissolution after reoxidation to $\mathbf{4}^{+} .^{55}$

Due to the orthogonal mer-coordination of the two tridentate ligands, the electronic influence of the different functional groups attached to the dpb ligand on the tpy ligand is reduced to a minor inductive effect. Consequently, the first reduction occurs at very similar potentials for all four complexes in the range between $-1.86\left(\mathrm{COOH}\right.$-substituted $\left.4\left(\mathrm{PF}_{6}\right)\right)$ and $-1.95 \mathrm{~V}$ $\left(\mathrm{NH}_{2}\right.$-substituted $\left.2\left(\mathrm{PF}_{6}\right)\right)$ spanning just $90 \mathrm{mV}$. Accordingly, the HOMO-LUMO gap, which is closely correlated to the difference of the redox potentials of the first reduction and oxidation, varies considerably in the order $4^{+} \approx 3^{+}>1^{+}>2^{+}$ (Table 1). This trend is in excellent agreement with DFT calculations (Fig. 2 and Table 1). 
All complexes exhibit follow-up oxidation peaks in the range between -1 and $-0.5 \mathrm{~V}$ once reduction has been carried out beyond $-2 \mathrm{~V}$. We had observed such behaviour previously both in mono- and dinuclear bis(terpyridine)ruthenium(II) complexes and cyclometalated ruthenium complexes bearing amide functionalities. We had suggested that these follow-up oxidations are associated with species that are formed after reduction of the substantially acidified amide $\mathrm{NH}$ proton (hydrogen formation).$^{55}$ The observation of similar processes in complexes such as $\mathbf{3}\left(\mathrm{PF}_{6}\right)$ and $\mathbf{4}\left(\mathrm{PF}_{6}\right)$ lacking $\mathrm{NH}$ functionalities contradicts this hypothesis. In fact, such more or less pronounced follow-up reoxidation peaks can be found for a large variety of tpy containing complexes of different metals such as chromium, ${ }^{69}$ manganese,${ }^{70}$ and ruthenium, ${ }^{35}$ once a sufficient number of reduction events have taken place at the tpy unit. The triplet spin densities of the twofold reduced complexes $\mathbf{1}^{1-}-\mathbf{4}^{1-}$ do not provide further hints on possible follow-up reactions (ESI, Table S2 $\dagger$ ). Compared to the respective ${ }^{1} \mathrm{GS}$ structures, their geometries are undistorted with a spin density homogeneously distributed over all three pyridine rings of the terpyridine ligand.

For the dinuclear complex $6\left(\mathrm{PF}_{6}\right)_{2}$, cyclovoltammetric studies reveal a single reversible two-electron reduction, as evidenced from square-wave voltammetry, followed by an intense stripping peak. Again, this stripping peak arises from precipitation of the large uncharged complex $6^{0}$ on the electrode surface and redissolution after reoxidation to $6^{2+}$. The first, unsplit reduction processes are ascribed to tpy-centered reductions occurring at both terminal ligands of the bimetallic complex as evidenced from DFT calculated triplet spin densities of $6^{0}$ (ESI, Table S3 and Fig. S17†). Additionally, two reversible oxidation processes at 0.05 and $0.29 \mathrm{~V}$, respectively, are observed. Based on the redox potentials of the mononuclear complexes, these can be ascribed to a primary oxidation of the NH-substituted complex fragment followed by oxidation of the CO-substituted moiety. Interestingly, the difference of the two oxidation potentials is slightly increased by $20 \mathrm{mV}$ compared to that of the mononuclear complexes $1^{+}$and $3^{+}$(240 versus $220 \mathrm{mV}$, Table 1). This might be due to spatial charge accumulation or to a weak electronic communication between the two complex fragments in the mixed-valent state $6^{3+}$. Missing shifts of the electrochemical potentials of asymmetric dinuclear complexes compared to similar mononuclear complexes or negligible splittings between the $\mathrm{Ru}^{\mathrm{II}} \mathrm{Ru}^{\mathrm{II}} / \mathrm{Ru}^{\mathrm{II}} \mathrm{Ru}^{\mathrm{III}}$ and the $\mathrm{Ru}^{\mathrm{II}} \mathrm{Ru}^{\mathrm{III}} / \mathrm{Ru}{ }^{\mathrm{III}} \mathrm{Ru}^{\mathrm{III}}$ oxidation potentials in symmetrical complexes have already been observed with other bimetallic bis(tridentate)ruthenium complexes. ${ }^{53-55,57}$ Some of these were accompanied by a weak electronic interaction between the $\mathrm{Ru}$ centers while others showed no metal-metal interaction. These examples illustrate that a clear conclusion as to whether electronic communication occurs between the metal centers of the complex fragments is impossible purely based on these electrochemical data. $^{71}$ UV-Vis spectroscopy studies on the mixed-valent species $6^{3+}$ will provide deeper insight into that matter (vide infra).

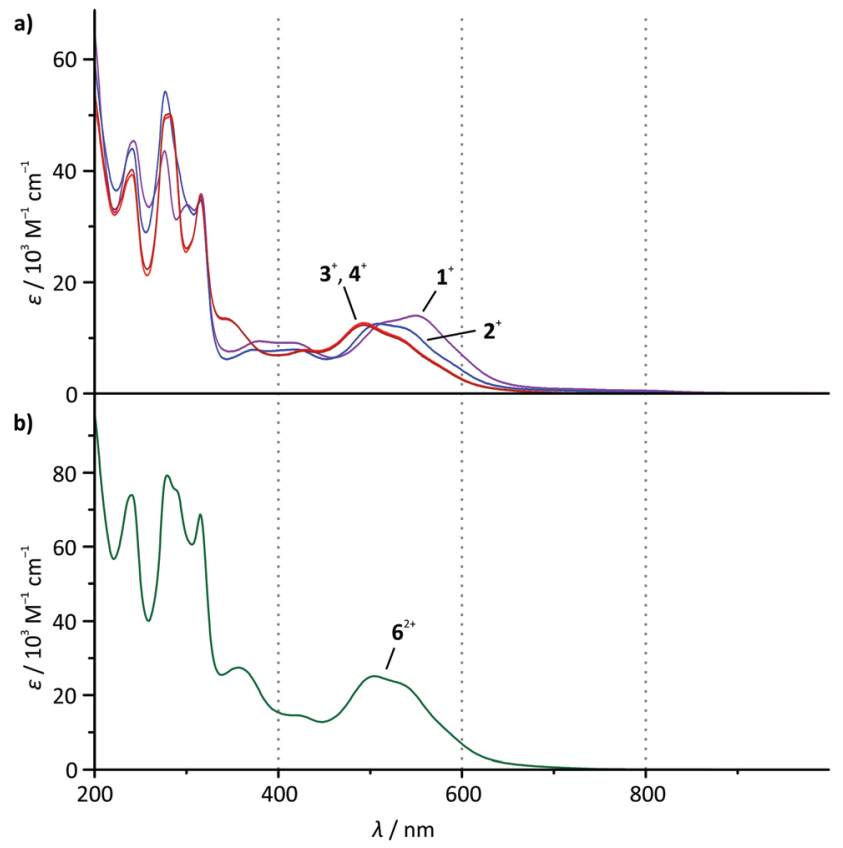

Fig. 3 UV-Vis absorption spectra of (a) $1\left(\mathrm{PF}_{6}\right)-4\left(\mathrm{PF}_{6}\right)$ and (b) $6\left(\mathrm{PF}_{6}\right)_{2}$ in dry acetonitrile solution at room temperature $\left(c=2 \times 10^{-5} \mathrm{~mol} \mathrm{l}^{-1}\right)$.

\section{UV-Vis spectroscopic properties of complexes $1\left(\mathrm{PF}_{6}\right)-4\left(\mathrm{PF}_{6}\right)$ and $6\left(\mathrm{PF}_{6}\right)_{2}$}

The absorption spectra of all mononuclear complexes (Fig. 3) exhibit very similar features. Besides intense transitions in the UV region attributed to $\pi-\pi^{*}$ transitions within the ligands, four discernible absorption bands are observed in the visible range between 350 and $650 \mathrm{~nm}$. DFT calculations ${ }^{30,39}$ and resonance Raman spectroscopy studies ${ }^{40}$ suggest that such bands characteristic for cyclometalated ruthenium complexes containing polypyridine and $\mathrm{N}^{\wedge} \mathrm{C}, \mathrm{N}^{\wedge} \mathrm{C}^{\wedge} \mathrm{N}$ or $\mathrm{N}^{\wedge} \mathrm{N}^{\wedge} \mathrm{C}$ ligands arise from metal-to-ligand charge transfer transitions ( $\left.{ }^{1} \mathrm{MLCT}\right)$ involving both the polypyridine and the cyclometalating ligand as electron accepting sites.

As the visible-range absorption bands are governed by ${ }^{1}$ MLCT transitions involving both ligands, variation of the functional group on the cyclometalating ligand greatly affects the position of the low-energy absorption maximum (Table 2). While the ester- or acid-substituted complexes $3^{+}$and $4^{+}$ exhibit absorption maxima at $493 \mathrm{~nm}$, the respective maximum of amide-substituted $\mathbf{1}^{+}$is observed at $509 \mathrm{~nm}$ and that of the amine complex $2^{+}$is found at $550 \mathrm{~nm}$ (Fig. 3). This trend is in good agreement with the HOMO-LUMO gap (Table 1 and Fig. 2) in this series of complexes. In contrast, DFT calculations reveal that the most intense Ru $\rightarrow$ tpy MLCT transitions (HOMO-1 $\left(\mathrm{d}_{x z}\right) \rightarrow$ LUMO) are not responsible for the observed trend since they appear at very similar energies for all four complexes (transition 5 in ESI, Tables S4-S7 $\dagger$ ). This is easily understood based on a closer examination of the orbitals of the complexes $\mathbf{1}^{+}-\mathbf{4}^{+}$involved in this transition (Fig. 2 and ESI, Table S1 $†$ ): the symmetry of the LUMO (tpy) only allows for constructive interference with the $d_{x z}$ orbital of the 
Table 2 Experimental UV-Vis absorption and emission data of the mononuclear complexes $1\left(\mathrm{PF}_{6}\right), \mathbf{2}\left(\mathrm{PF}_{6}\right), \mathbf{3}\left(\mathrm{PF}_{6}\right)$, and $4\left(\mathrm{PF}_{6}\right)$ as well as the dinuclear complex $6\left(\mathrm{PF}_{6}\right)_{2}$. Absorption and emission data are obtained from (deaerated) acetonitrile solution, and low-temperature emission data are recorded in butyronitrile. Excitation wavelengths are given in parentheses where wavelength dependence of the emission maximum was observed, otherwise $\lambda_{\text {exc }}=500 \mathrm{~nm}$

\begin{tabular}{|c|c|c|c|c|c|}
\hline & $\lambda_{\max } / \mathrm{nm}\left(\varepsilon / 10^{3} \mathrm{M}^{-1} \mathrm{~cm}^{-1}\right)$ & $\begin{array}{l}\lambda_{\mathrm{em}} / \mathrm{nm} \\
\text { at } 298 \mathrm{~K}\end{array}$ & $\begin{array}{l}\lambda_{\mathrm{em}} / \mathrm{nm} \\
\text { at } 155 \mathrm{~K}\end{array}$ & $\begin{array}{l}\lambda_{\mathrm{em}} / \mathrm{nm} \\
\text { at } 77 \mathrm{~K}\end{array}$ & $\begin{array}{l}\phi \text { at } \\
298 \mathrm{~K}\end{array}$ \\
\hline $\mathbf{1}\left(\mathrm{PF}_{6}\right)$ & 533 (11.9, sh), 509 (12.5), 419 (7.9), 373 (7.9), 315 (34.8) & 800 & 798 & 736 & $8 \times 10^{-6}$ \\
\hline $3\left(\mathrm{PF}_{6}\right)$ & $529(9.9, \mathrm{sh}), 493(12.3), 428$ (7.6), 343 (13.5), 315 (35.3) & 744 & 738 & 708 & $14 \times 10^{-6}$ \\
\hline $4\left(\mathrm{PF}_{6}\right)$ & 529 (10.2, sh), 493 (12.7), 429 (7.8), 343 (13.3), 315 (35.6) & 744 & 738 & 709 & $15 \times 10^{-6}$ \\
\hline $6\left(\mathrm{PF}_{6}\right)_{2}$ & $530(23.4, \mathrm{sh}), 504(25.1), 422$ (14.6), 356 (27.4), 315 (68.7) & 756 (480), $772(560)$ & 746 & 736 & $9 \times 10^{-6}$ \\
\hline
\end{tabular}

metal (HOMO-1). On the other hand, both, HOMO-1 and LUMO are perpendicular to the $\mathrm{Ru} \mathrm{d}_{y z}$ orbital and the $\mathrm{dpb}$ $\pi$-orbital which strongly contribute to the HOMO. Hence, the $\mathrm{dpb}$ functional group's impact on the involved orbitals is again reduced to a minor inductive effect explaining the weak dependence of the $\mathrm{Ru} \rightarrow$ tpy MLCT transitions on the $\mathrm{dpb}$ substituent.

The strong bathochromic shift of the experimental absorption maximum accompanying the more electron-donating $N$-acetyl amino and amino substituents at the dpb ligand in fact arises from symmetry-allowed $\mathrm{d}_{y z}(\mathrm{Ru}) \rightarrow$ dpb MLCT transitions. Especially the HOMO $\rightarrow \mathrm{LUMO}+2$ transition plays a key role within the absorption characteristics (transition 6 in Tables S4-S7 $\dagger)$. These transitions are calculated at $486\left(\mathbf{1}^{+}\right)$, $507\left(2^{+}\right)$, and $456 \mathrm{~nm}\left(3^{+}\right.$and $\left.4^{+}\right)$, respectively, and they nicely reproduce the trends within the absorption maxima of the respective complexes (Table 2). This fully confirms that the two main ${ }^{1}$ MLCT transitions in the visible range of the electronic spectrum, namely $\mathrm{d}_{x z}(\mathrm{Ru}) \rightarrow$ tpy and $\mathrm{d}_{y z}(\mathrm{Ru}) \rightarrow \mathrm{dpb}$, are electronically decoupled for simple symmetry reasons.

At first sight, the absorption spectrum of the dinuclear complex $6^{2+}$ resembles the absorption spectra of the carboxysubstituted mononuclear complexes $3^{+}$and $\mathbf{4}^{+}$with roughly doubled extinction coefficients due to its dinuclear nature (Fig. 3). A closer inspection reveals that the spectrum of the dinuclear complex is much better reproduced by a $1: 1$ superposition of the absorption spectra of the ester- and the amidesubstituted mononuclear complexes $\mathbf{1}^{+}$and $3^{+}$(Fig. 4). This suggests that the dinuclear compound $\mathbf{6}^{2+}$ consists of two essentially non-interacting bis(tridentate)ruthenium(II) fragments connected via an amide bond. Indeed, this is underlined by time-dependent DFT calculations which reveal that all charge transfer excitations $>400 \mathrm{~nm}$ between the two complex fragments have negligible oscillator strengths and should play no role in the observed absorption features (Table S8†). Similar observations have previously been made for other amide-linked dinuclear ruthenium(II) complexes with tridentate ligands. ${ }^{53-55}$ Since in this study the visible absorptionspectroscopic fingerprints of the two subunits are more distinct than in the literature-known bimetallic examples, the superimposed nature of the absorption bands of $6^{2+}$ is more obvious. In principle, the two $[\mathrm{Ru}(\mathrm{dpb})(\mathrm{tpy})]^{+}$subunits are essentially uncoupled in the $\mathrm{Ru}^{\mathrm{II}} \mathrm{Ru}^{\mathrm{II}}$ state.

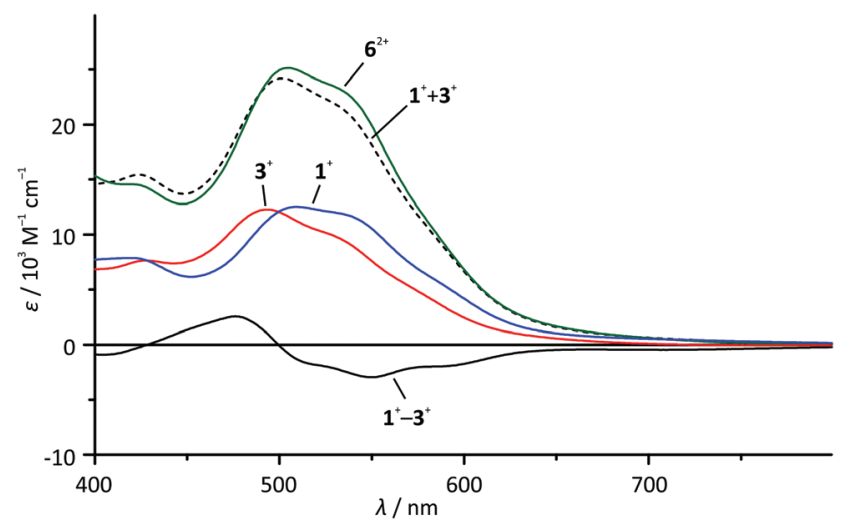

Fig. 4 Visible range of the absorption spectra of $1^{+}$(blue), $3^{+}$(red) and $6^{2+}$ (green) in dry acetonitrile solution as well as superposition $\left(1^{+}+3^{+}\right)$ (black, dashed line) and difference spectra $\left(3^{+}-1^{+}\right)$(black, solid line).

To probe the metal-metal interaction in the mixed-valent state $6^{3+}$, careful in situ chemical oxidation of $6\left(\mathrm{PF}_{6}\right)_{2}$ in acetonitrile solution was carried out using $\left(\mathrm{NH}_{4}\right)_{2}\left[\mathrm{Ce}\left(\mathrm{NO}_{3}\right)_{6}\right]$ as an oxidant $\left(E \approx 0.8-0.9\right.$ V).$^{72}$ Its oxidation potential is high enough to allow for a stepwise double oxidation of $6^{2+}$ to the bis(ruthenium(III)) complex $6^{4+}$. Absorption spectra (Fig. 5) were recorded each time after addition of 0.25 equivalents of the oxidant. A broad, symmetrical absorption band appears in the near infrared (NIR) region of the absorption spectrum upon addition of $0 \rightarrow 1$ equivalents of the oxidant with an absorption maximum at $1165 \mathrm{~nm}\left(8585 \mathrm{~cm}^{-1}, \varepsilon_{\max }=2620 \mathrm{M}^{-1}\right.$ $\mathrm{cm}^{-1}$, full width at half maximum $\tilde{\nu}_{1 / 2}=6020 \mathrm{~cm}^{-1}$ ). Simultaneously, a second, significantly sharper band appears in the red region (maximum at $716 \mathrm{~nm}$ ). A set of isosbestic points is observed for the oxidation of $6^{2+}$ to $6^{3+}$ at $233,326,335,486$, and $619 \mathrm{~nm}$ indicating a clean reaction without side products. Upon addition of more oxidant $(1 \rightarrow 1.5$ eq.), a new set of isosbestic points is observed at $273,325,335,638$, and $810 \mathrm{~nm}$. Hence, the reaction $6^{2+} \rightarrow 6^{3+} \rightarrow 6^{4+}$ occurs stepwise as expected from the separation of the first and second oxidation waves in the cyclic voltammogram of $\mathbf{6}^{2+}$. Simultaneously, the intensity of the NIR band decreases while the band in the red region rises further. Interestingly, upon addition of more oxidant $(1.5 \rightarrow 2$ eq.), the isosbestic points are lost and a new absorption band appears at around $940 \mathrm{~nm}$ (ESI, Fig. S18†े). 


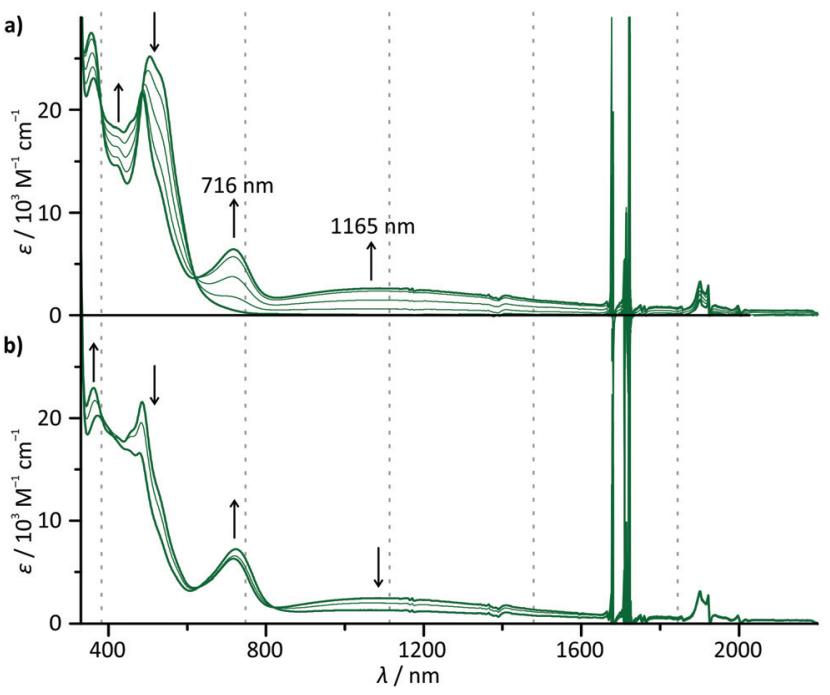

Fig. 5 UV-Vis-NIR absorption spectra of $6^{2+}$ in acetonitrile solution upon addition (a) of $0 \rightarrow 1$ equivalents of $\left(\mathrm{NH}_{4}\right)_{2}\left[\mathrm{Ce}\left(\mathrm{NO}_{3}\right)_{6}\right]$ as an oxidant and (b) of $1 \rightarrow 1.5$ equivalents of $\left(\mathrm{NH}_{4}\right)_{2}\left[\mathrm{Ce}\left(\mathrm{NO}_{3}\right)_{6}\right]$ as an oxidant. Spectra are recorded after addition of 0.25 equivalents each time.

We ascribe this to the decomposition of the highly charged complex $6^{4+}$ on the timescale of the measurement (about 45 minutes).

The fact, that the NIR band is only present in the mixedvalent state $6^{3+}$, allows for the conclusion that it arises from an intervalence charge transfer (IVCT) process between the two metal centers $\mathrm{Ru}^{\mathrm{II}} \rightarrow \mathrm{Ru}^{\mathrm{III}}$. The absorption band in the red spectral region on the other hand is ascribed to ligand-tometal (LMCT) transitions in the newly formed $\mathrm{Ru}^{\mathrm{III}}$ fragment $(\mathrm{dpb} \rightarrow \mathrm{Ru})$. This is supported by TD-DFT calculations which predict such a symmetry allowed IVCT transition $\left(\mathrm{d}_{y z}(\mathrm{Ru})+\right.$ $\left.\mathrm{dpb}-\mathrm{CO} \rightarrow \mathrm{d}_{y z}(\mathrm{Ru})+\mathrm{dpb}-\mathrm{NH}\right)$ to occur at a wavelength of $1395 \mathrm{~nm}$ and LMCT excitations at around $630 \mathrm{~nm}$ for $6^{3+}$ (ESI, Table S9 $\dagger$ ). Additionally, the absorption spectra of the mononuclear complexes $\mathbf{1}^{+}$and $3^{+}$exhibit very similar LMCT bands in the range between 600 and $800 \mathrm{~nm}$ upon oxidation under the same conditions (ESI, Fig. S19†). In particular, the excellent agreement between the LMCT maximum of $\mathbf{1}^{2+}(720 \mathrm{~nm})$ and $6^{3+}(716 \mathrm{~nm})$ underlines that the first oxidation of $6^{2+}$ occurs at the $\mathrm{N}$-substituted $\left[\mathrm{Ru}(\mathrm{dpb})(\text { tpy) }]^{+}\right.$fragment.

Although a straight-forward Hush analysis of the band shape and energy of the IVCT band is formally not correct due to the energy difference $\Delta G_{0}$ of the two valence isomers [(tpy) $\left.\mathrm{Ru}^{\mathrm{II}}(\mathrm{dpb}-\mathrm{NHCO}-\mathrm{dpb}) \mathrm{Ru}^{\mathrm{III}}(\mathrm{tpy})\right]^{3+}$ and $\left[(\mathrm{tpy}) \mathrm{Ru}^{\mathrm{III}}(\mathrm{dpb}-\mathrm{NHCO}-\right.$ $\left.\mathrm{dpb}) \mathrm{Ru}^{\mathrm{II}}(\mathrm{tpy})\right]^{3+}$, the latter being the lower energy isomer, we analysed the IVCT band to obtain a rough estimate of the electronic coupling parameter $V_{\text {ab }}$ (ESI, Fig. S20 $\dagger$ ). ${ }^{49,73}$ As the donor-acceptor distance $r_{\mathrm{MM}}$, the $\mathrm{Ru}-\mathrm{Ru}$ distance of $13.1 \AA$ (from DFT calculation) was taken into account despite the fact that the involved orbitals are substantially delocalized towards the cyclometalated bridging ligand, thus rendering the effective charge transfer distance smaller. ${ }^{59,60,74-76}$ As using a too large value for $r_{\mathrm{MM}}$ will underestimate the electronic coup- ling parameter, the calculated $V_{\mathrm{ab}}$ value of $580 \mathrm{~cm}^{-1}$ represents a lower limit. This coupling in $6^{3+}$ is roughly half as strong as in the back-to-back linked symmetrical dinuclear complex $\left[(\right.$ ttpy $) \mathrm{Ru}(\mathrm{dpb} \text {-dpb)Ru(ttpy) }]^{3+}$ (ttpy $=44^{\prime}$-tolylterpyridine).$^{59} \mathrm{We}$ attribute this weakening to the redox asymmetry introduced by the amide bridge in $6^{3+}$. Simultaneously, the NHCO group increases the donor-acceptor distance and reduces the orbital overlap between the two complex moieties. Clearly, the mixedvalent complex $6^{3+}$ has to be assigned to the Robin-Day class II with localized valencies and a moderate electronic coupling between the complex subunits. ${ }^{48}$ The activation barrier for thermal electron transfer can be calculated when the strength of electronic coupling and the energy difference $\Delta G_{0}$ of the two valence isomers are known. ${ }^{52}$ The latter can be estimated based on the difference in redox potentials of the $\mathrm{Ru} / \mathrm{RI} \mathrm{u}^{\mathrm{III}}$ couple of the two complex subunits. Since for $6^{2+}$, this difference is shifted towards larger values due to charge accumulation and the resonance stabilization of the mixed-valent species $6^{3+}$, we used the difference in $\mathrm{Ru}^{\mathrm{II}} / \mathrm{Ru}^{\mathrm{III}}$ redox potentials of the mononuclear complexes $\mathbf{1}^{+}$and $3^{+}$to estimate $\Delta G_{0}$ as $0.22 \mathrm{eV}\left(1775 \mathrm{~cm}^{-1}, 21 \mathrm{~kJ} \mathrm{~mol}^{-1}\right) .{ }^{52}$ This yields an activation barrier of the electron transfer from [(tpy)Ru ${ }^{\mathrm{III}}(\mathrm{dpb}-\mathrm{NHCO}-$ dpb)Ru $\left.{ }^{\mathrm{II}}(\mathrm{tpy})\right]^{3+}$ to $\left[(\mathrm{tpy}) \mathrm{Ru}^{\mathrm{II}}(\mathrm{dpb}-\mathrm{NHCO}-\mathrm{dpb}) \mathrm{Ru}^{\mathrm{III}}(\mathrm{tpy})\right]^{3+}$ of $2190 \mathrm{~cm}^{-1}\left(26 \mathrm{~kJ} \mathrm{~mol}^{-1}\right)$.

The electronic coupling in $6^{3+}$ is in contrast to the amide bridged dinuclear ruthenium complex [(EtOOC-tpy)Ru ${ }^{\mathrm{II}}$ (tpyNHCO-tpy)Ru ${ }^{\text {III }}$ (tpy-NHCOMe) $]^{5+} \cdot{ }^{55}$ Based on a simple molecular orbital consideration, the electronic coupling occurs via a superexchange mechanism involving the bridge's frontier orbitals. $^{77,78}$ In the bis(terpyridine)ruthenium system, these are well separated in energy from the donor and acceptor orbitals at the metal centers. Thus, the tunnel barrier for electron transfer is much higher than in $6^{3+}$ leading to no detectable electronic interaction in the former. In contrast, the mediating bridge orbitals of $6^{3+}$ are already mixed into the ground state donor and acceptor orbitals of the metal centers, significantly increasing the electronic coupling in $6^{3+} \cdot 55$ Obviously, cyclometalating bridging ligands enable electronic communication in mixed-valent $\mathrm{Ru}^{\mathrm{II}} / \mathrm{Ru}^{\mathrm{III}}$ complexes. ${ }^{59,60,75,76}$

\section{Emission spectroscopy and triplet excited states of complexes 1 $\left(\mathrm{PF}_{6}\right)-\mathbf{4}\left(\mathrm{PF}_{6}\right)$}

All four mononuclear complexes $\mathbf{1}\left(\mathrm{PF}_{6}\right)-\mathbf{4}\left(\mathrm{PF}_{6}\right)$ exhibit very weak room temperature emission in the red spectral range (Fig. 6 and Table 2). The carboxy-substituted complexes $3^{+}$and $4^{+}$show the highest energy emission along with the highest phosphorescence quantum yield. Both are in excellent agreement with the values for the methyl ester complex reported by van Koten and coworkers. ${ }^{30}$ Interestingly, the phosphorescence of these complexes is not quenched by oxygen present during the measurement. This is attributed to very short excited state lifetimes in the picosecond range that are too short for bimolecular quenching processes by triplet oxygen to occur. Indeed, attempts to measure the luminescence lifetimes by timecorrelated single photon counting failed underlining that the 

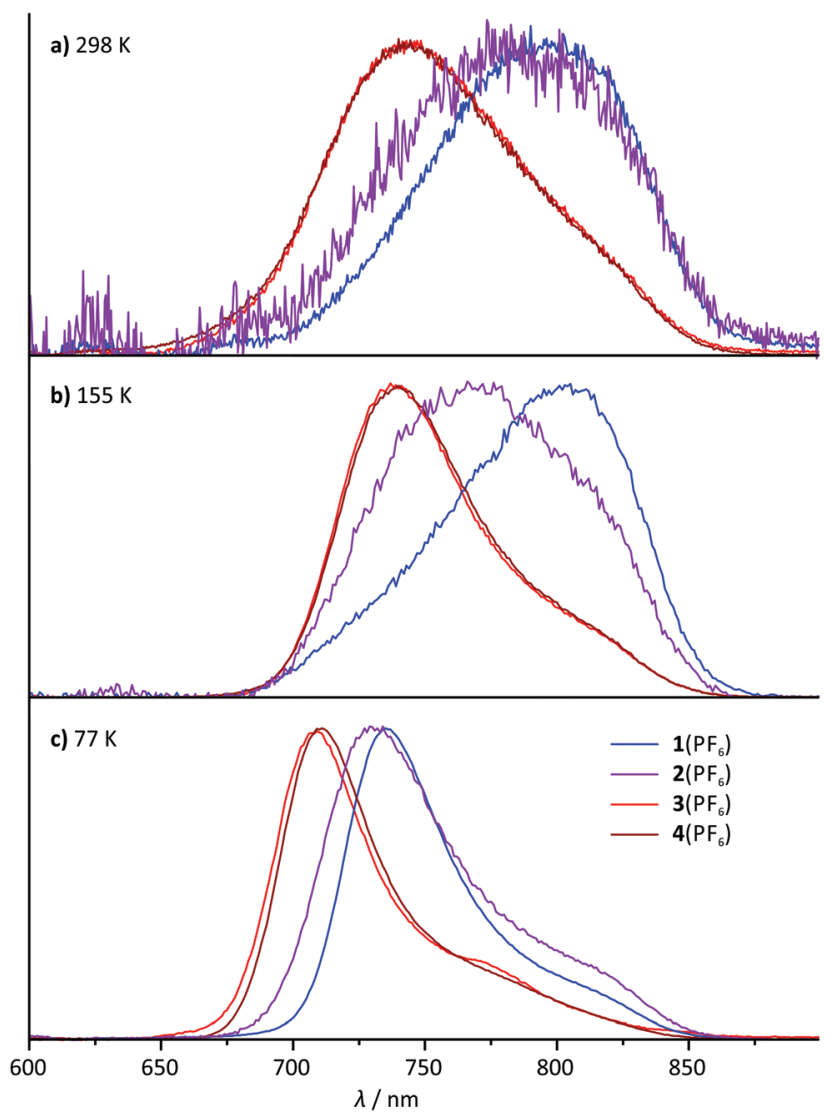

Fig. 6 Normalized steady-state emission spectra of $1\left(\mathrm{PF}_{6}\right)-4\left(\mathrm{PF}_{6}\right)\left(\lambda_{\text {exc }}\right.$ $=500 \mathrm{~nm})(\mathrm{a})$ at room temperature in degassed acetonitrile solution, (b) at $155 \mathrm{~K}$ in liquid butyronitrile solution and (c) at $77 \mathrm{~K}$ in a frozen butyronitrile matrix.

excited state lifetimes at room temperature are well below one nanosecond.

The shape of the emission band of the two COOR-substituted compounds $3^{+}$and $4^{+}$is very similar to that of many other (polypyridine)ruthenium(II) complexes with a vibronic progression resulting in a typical low-energy shoulder. ${ }^{2,27,31,40}$ The emission band shape of the $N$-substituted complexes $\mathbf{1}^{+}$and $\mathbf{2}^{+}$ on the other hand is different. Spectral decomposition in separate Gaussian shaped bands (ESI, Fig. S21 $\dagger$ ) suggests that $0-1$ and especially $0-2$ transitions dominate in these complexes at room temperature. The $0-0$ transition, which typically is quite strong in other $[\mathrm{Ru}(\mathrm{dpb})(\mathrm{tpy})]^{+}$-complexes at room temperature, apparently is of less relevance in complexes with dpbNHR ligands (ESI, Fig. S21†). Consequently, in a solid butyronitrile matrix at $77 \mathrm{~K}$, a more pronounced hypsochromic shift is observed for complexes $\mathbf{1}^{+}\left(1085 \mathrm{~cm}^{-1}\right)$ and $\mathbf{2}^{+}\left(860 \mathrm{~cm}^{-1}\right)$ than for $3^{+}$and $4^{+}\left(580 \mathrm{~cm}^{-1}\right)$. At $77 \mathrm{~K}$ in frozen butyronitrile solution, the carboxy-substituted complexes $3^{+}$and $\mathbf{4}^{+}$emit at a wavelength of 708-709 nm, while the amido- and amino-substituted complexes $\mathbf{1}^{+}$and $\mathbf{2}^{+}$emit at 736 and $731 \mathrm{~nm}$, respectively. The similarity in the emission energy of the latter two complexes is remarkable and not straight-forwardly under- stood from a simple consideration of the HOMO-LUMO gap of the respective complexes (Table 1).

In order to gain a deeper understanding of the excited state properties of the respective complexes, DFT calculations on the excited triplet states were performed. The symmetry allowed emission of (polypyridine)ruthenium(II) complexes arises from a low-energy ${ }^{3}$ MLCT state. It exhibits spin density both at the metal site and the $\pi$-accepting polypyridine ligand. In fact, in cyclometalated complexes of the type $\left[\mathrm{Ru}\left(\mathrm{dpb}-\mathrm{R}^{1}\right)\right.$ $\left(\right.$ tpy- $\left.\left.\left.\mathrm{R}^{2}\right)\right]\right]^{+}$the LUMO of the terpyridine is always involved in the ${ }^{3}$ MLCT emissive state as well. ${ }^{40}$ Consequently, geometry optimizations were performed on the triplet states of all complexes under study yielding the respective ${ }^{3}$ MLCT states (Fig. 7). Despite the fact that these states are distorted to some extent compared to the singlet ground states $\left({ }^{1} \mathrm{GS}\right.$ ) (vide infra), it is obvious from the respective spin densities that the ${ }^{3} \mathrm{MLCT}$ states are composed of HOMO-1 $\left(\mathrm{d}_{x z}(\mathrm{Ru})\right)$ as the electron donor and LUMO $\left(\pi_{\text {tpy }}{ }^{*}\right)$ as the electron acceptor. Similar to the previous discussion concerning the ${ }^{1}$ MLCT excitations (vide supra), this orbital parentage of the ${ }^{3} \mathrm{MLCT}$ state results in rather similar ${ }^{3} \mathrm{MLCT}-{ }^{1} \mathrm{GS}$ energy gaps despite the strongly varying HOMO $\left(\mathrm{d}_{y z}+\pi_{\mathrm{dpb}}\right)$-LUMO gaps.

Insight into excited state deactivation pathways can be gained from temperature dependent measurements of excited state lifetimes or quantum yields. Seminal work by T. J. Meyer and co-workers ${ }^{22}$ revealed a metal-centered ${ }^{3} \mathrm{MC}$ state as a thermally accessible state in $\left[\mathrm{Ru}(\mathrm{bpy})_{3}\right]^{2+}$. This state depopulates the emissive ${ }^{3}$ MLCT state and substantially shortens its lifetime at room temperature. In strongly push-pull substituted cyclometalated complexes such as [Ru(dpb-NHCOMe)(tpyCOOEt)], a second pathway via a low-energy ligand-to-ligand $\left(\mathrm{dpb} \rightarrow\right.$ tpy) charge transfer $\left({ }^{3} \mathrm{LL} \mathrm{L}^{\prime} \mathrm{CT}\right)$ state is accessible that prevents emission entirely. ${ }^{40}$

Temperature-dependent steady-state emission spectra were recorded for complexes $\mathbf{1}\left(\mathrm{PF}_{6}\right)$ and $\mathbf{3}\left(\mathrm{PF}_{6}\right)$ in butyronitrile solution in the temperature range between $298 \mathrm{~K}$ and $155 \mathrm{~K}$ (Fig. 8). Due to the low quantum yield of complex $2\left(\mathrm{PF}_{6}\right)$ and the spectroscopic similarity of $3\left(\mathrm{PF}_{6}\right)$ and $4\left(\mathrm{PF}_{6}\right), 2\left(\mathrm{PF}_{6}\right)$ and $\mathbf{4}\left(\mathrm{PF}_{6}\right)$ were not considered in this variable temperature (VT) emission study. Interestingly, the VT emission plots $\ln (\phi)$ vs. $T^{-1}$ obtained for complexes $\mathbf{1}\left(\mathrm{PF}_{6}\right)$ and $\mathbf{3}\left(\mathrm{PF}_{6}\right)$ differ qualitatively from those of $\left[\mathrm{Ru}(\mathrm{bpy})_{3}\right]\left(\mathrm{PF}_{6}\right)_{2}$ (ESI, Fig. S22 and S23†) and the structurally related complex $[\mathrm{Ru}(\mathrm{dpb}-\mathrm{COOEt})(\mathrm{tpy}-$ $\mathrm{NHCOMe})]\left(\mathrm{PF}_{6}\right) .{ }^{40}$ The shape of the curves clearly is not linear as has been found for $[\mathrm{Ru}(\mathrm{dpb}-\mathrm{COOEt})(\mathrm{tpy}-\mathrm{NHCOMe})]^{+} .^{40}$ Meyer's equation ${ }^{22,23}$ which assumes a single thermally activated deactivation pathway $\left({ }^{3} \mathrm{MC}\right)$ for the emissive ${ }^{3} \mathrm{MLCT}$ state fails to reproduce the shape of the VT emission plots of $\mathbf{1}^{+}$and $3^{+}$as well, while it perfectly fits the VT emission plot of $\left[\mathrm{Ru}(\mathrm{bpy})_{3}\right]^{2+}$ (ESI, Fig. S22 and S23†).

A rational explanation for this behaviour was found upon extended DFT examination of the triplet potential energy surface. Besides the emissive ${ }^{3}$ MLCT state, two additional lowenergy triplet states could be localized as local minima for all four complexes $\mathbf{1}^{+}-\mathbf{4}^{+}$. These are assigned as ${ }^{3} \mathrm{MC}$ states with a spin density essentially found on the metal site and as ${ }^{3} \mathrm{LL} \mathrm{CT}^{\prime}$ 

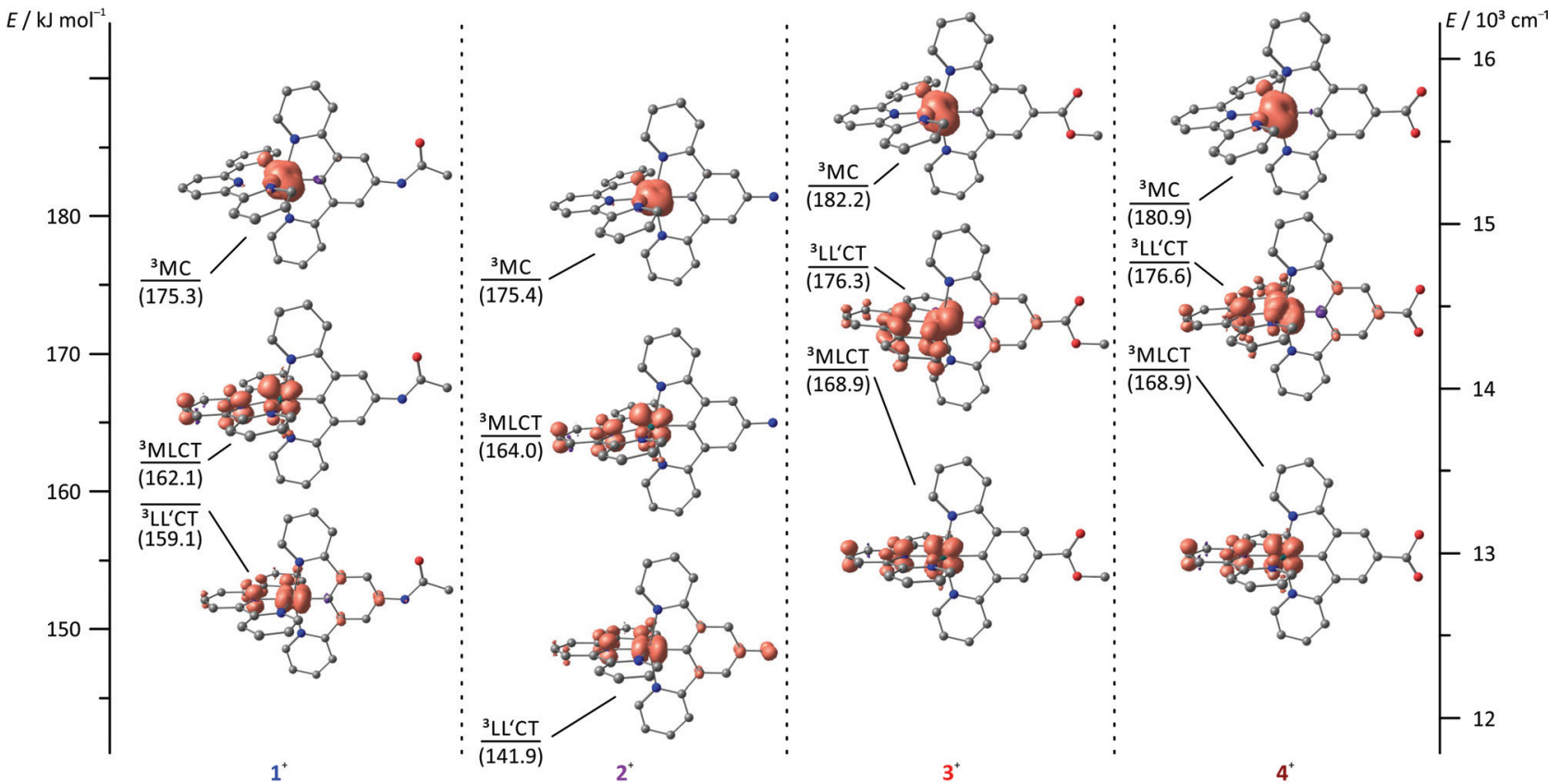

Fig. 7 Jablonski diagram of the triplet states of complexes $1^{+}-4^{+}$including DFT spin density plots (B3LYP, def2-SV(P), COSMO (acetonitrile), ZORA; contour value: 0.01 ). ${ }^{3} \mathrm{MLCT}$ energies are given as experimental $0-0$ emission energies, ${ }^{3} \mathrm{LL}^{\prime} \mathrm{CT}$ and ${ }^{3} \mathrm{MC}$ energies are calculated based on DFT derived Gibbs free energies relative to the respective ${ }^{3} \mathrm{MLCT}$ energy and given in $\mathrm{kJ} \mathrm{mol}^{-1}$. Hydrogen atoms are omitted for clarity.

states in which the tpy ligand can be formally regarded as singly reduced while the $\mathrm{Ru}-\mathrm{dpb}$ moiety carries an electron hole. ${ }^{40}$ This latter low-energy state was considered responsible for the lack of emission from the strongly donor-acceptor substituted complex $[\mathrm{Ru}(\mathrm{dpb}-\mathrm{NHCOMe})(\text { tpy-COOEt })]^{+}$because the orthogonality of the orbitals of the electron and hole prevents the radiative recombination from the ${ }^{3} \mathrm{LL}$ 'CT state. ${ }^{40}$

Remarkably, all triplet states exhibit characteristic distortions compared to the geometry of the respective singlet ground state structures with a strong resemblance between the COOR-substituted complex on one side and the NHR-substituted complex on the other (Fig. 7). In the ${ }^{3}$ MLCT states of complexes $3^{+}$and $4^{+}$, the arrangement of the ligand periphery is essentially unaltered while the metal center is shifted towards the tpy ligand. The $\mathrm{Ru}-\mathrm{N}^{\mathrm{tpy}}$ central bond length is shortened by 2 pm ( ${ }^{1} \mathrm{GS}: 204 \mathrm{pm},{ }^{3} \mathrm{MLCT}$ : $206 \mathrm{pm}$ for $3^{+}$and $\left.4^{+}\right)$while the $\mathrm{Ru}-\mathrm{C}^{\mathrm{dpb}}$ bond is elongated by $4 \mathrm{pm}$ in both cases $\left({ }^{1} \mathrm{GS}: 195 \mathrm{pm},{ }^{3}\right.$ MLCT: $199 \mathrm{pm}$ for $\mathbf{3}^{+}$and $\left.\mathbf{4}^{+}\right)$. This is in agreement with an increased coulombic interaction between the formally oxidized $\mathrm{Ru}$ and reduced tpy ligands upon population of the ${ }^{3}$ MLCT state and has been described before for other polypyridine ruthenium complexes. ${ }^{35,40}$ All $\mathrm{Ru}-\mathrm{N}$ bonds involving the four peripheral pyridines are nearly unaffected with similar bond lengths between $210 \mathrm{pm}$ and $212 \mathrm{pm}$ in all cases. This is in stark contrast to the geometry of the ${ }^{3}$ MLCT state of both $\mathbf{1}^{+}$and $2^{+}$. Here, the ligand periphery is substantially distorted compared to the ${ }^{1} \mathrm{GS}$ geometry: the central pyridine ring of the tpy unit is offset from the plane perpendicular to the dpb ligand with a central $\mathrm{N}^{\text {tpy }}-\mathrm{Ru}-\mathrm{C}^{\mathrm{dpb}}$ bond angle of just $167^{\circ}$. At the same time, one of the two peripheral pyridine rings of the dpb unit is shifted away from the metal center to some extent yielding a long $\mathrm{Ru}-\mathrm{N}$ bond of $219 \mathrm{pm}$ while the trans $\mathrm{Ru}-\mathrm{N}$ bond is shortened to $209 \mathrm{pm}$ (from $212 \mathrm{pm}$ in the ${ }^{1} \mathrm{GS}$ of $\mathbf{1}^{+}$and $\mathbf{2}^{+}$). A similar shift of the metal center towards the tpy ligand as observed for $\mathbf{3}^{+}$and $\mathbf{4}^{+}$is also found for $\mathbf{1}^{+}$ and $2^{+}$. This difference in the geometry of the ${ }^{3}$ MLCT states between the NHR- and COOR-substituted complexes might explain the dominance of $0-2$ transitions in the emission spectra of $\mathbf{1}^{+}$and $2^{+}$as it corresponds to a larger horizontal offset on the ${ }^{1} \mathrm{GS}^{3}{ }^{3} \mathrm{MLCT}$ reaction coordinate.

In the ${ }^{3}$ LL'CT states again a clear distinction is found between the geometries of complexes $\mathbf{1}^{+}$and $2^{+}$on one side and $3^{+}$and $4^{+}$on the other. The ${ }^{3} \mathrm{LL}^{\prime} \mathrm{CT}$ geometries of complexes $\mathbf{1}^{+}$and $2^{+}$appear essentially undistorted compared to the ${ }^{1} \mathrm{GS}$ structures with a slight elongation of the central Ru$\mathrm{N}^{\text {tpy }}$ bond by about $4 \mathrm{pm} .{ }^{40} \mathrm{~A}$ similar shift is observed in the ${ }^{3} \mathrm{LL}$ CT states of complexes $3^{+}$and $4^{+}$. Yet, in their ${ }^{3} \mathrm{LL}^{\prime} \mathrm{CT}$ geometries, the tpy ligand is twisted by about $8^{\circ}$ out of the plane perpendicular to the dpb ligand.

The ${ }^{3} \mathrm{MC}$ states of all four complexes appear structurally similar with immensely elongated bond lengths between Ru and the tpy nitrogen atoms (central Ru- $\mathrm{N}^{\text {tpy }}$ bonds: 225-227 $\mathrm{pm}$, peripheral $\mathrm{Ru}-\mathrm{N}^{\mathrm{tpy}}$ bonds: $235-237 \mathrm{pm}$ ). This distortion is accompanied by a tilt of the peripheral pyridine rings compared to the central one within the tpy unit by $9-11^{\circ}$. The dpb ligand on the other side is undistorted with typical $\mathrm{Ru}-\mathrm{dpb}$ bond lengths (central Ru-C $\mathrm{C}^{\mathrm{dpb}}$ bonds: 195-196 pm, peripheral $\mathrm{Ru}-\mathrm{N}^{\mathrm{dpb}}$ bonds: $215-217 \mathrm{pm}$ ).

Based on DFT calculated Gibbs free energies, the ${ }^{3} \mathrm{LL} \mathrm{CT}^{\prime}$ state is the triplet ground state of the NHR-substituted com- 

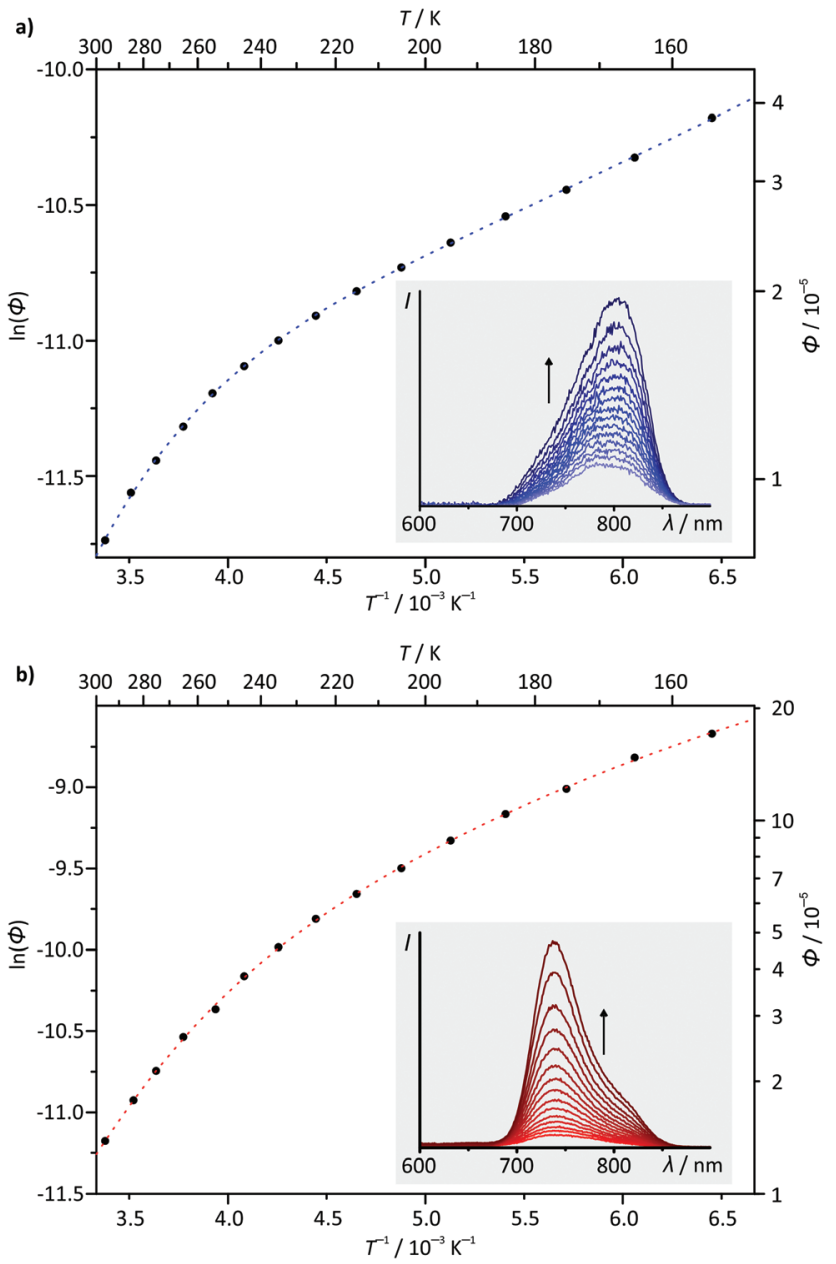

Fig. 8 Variable-temperature emission plots of $\ln (\phi)$ vs. $T^{-1}$ for complexes (a) $1\left(\mathrm{PF}_{6}\right)$ and $(\mathrm{b}) \mathbf{3}\left(\mathrm{PF}_{6}\right)$ including fit curves (dashed lines; see the text for fit function and parameters). The insets show emission spectra in the range between $298 \mathrm{~K}$ and $155 \mathrm{~K}$.

plexes $\mathbf{1}^{+}$and $2^{+}$(Fig. 7) followed by the ${ }^{3} \mathrm{MLCT}$ and ${ }^{3} \mathrm{MC}$ states. This order is identical to that of the strongly donoracceptor substituted complex [Ru(dpb-NHCOMe)(tpyCOOEt)] ${ }^{+}{ }^{40}$ In complexes $3^{+}$and $4^{+}$, in which the donor strength of the dpb ligand is weakened by the COOR substituents, the order of ${ }^{3} \mathrm{MLCT}$ and ${ }^{3} \mathrm{LL}$ 'CT is inverted. Increasing the push-pull substitution of a given heteroleptic $[\mathrm{Ru}(\mathrm{dpb})$ (tpy) $]^{+}$complex will lower the energy of a donor-acceptor charge-separated state, here the ${ }^{3} \mathrm{LL}$ 'CT state, relative to the other excited states. Remarkably, the trends of the geometrical features of the various states can be related to their relative energies. While for $\mathbf{1}^{+}$and $\mathbf{2}^{+}$, the ${ }^{3} \mathrm{LL}^{\prime} \mathrm{CT}$ state is the least distorted compared to the ${ }^{1} \mathrm{GS}$ geometries, for $3^{+}$and $\mathbf{4}^{+}$this is true for the ${ }^{3}$ MLCT state instead.

Considering the relative energies of the various triplet states, it is apparent that the emissive ${ }^{3} \mathrm{MLCT}$ state is flanked by two non-emissive states $\left({ }^{3} \mathrm{MC}\right.$ and $\left.{ }^{3} \mathrm{LL} \mathrm{CT}^{\prime}\right)$ for all four complexes. Both are thermally accessible, instead of just a single state $\left({ }^{3} \mathrm{MC}\right)$ as in $\left[\mathrm{Ru}(\mathrm{bpy})_{3}\right]\left(\mathrm{PF}_{6}\right)_{2}$. The presence of a second non-emissive state at low energy gives rise to an additional excited state deactivation pathway. ${ }^{40}$ This is important for the interpretation of the temperature dependence of the emission spectra of $\mathbf{1}\left(\mathrm{PF}_{6}\right)$ and $\mathbf{3}\left(\mathrm{PF}_{6}\right)$ (Fig. 8). In fact, a second exponential term needs to be taken into account, compared to Meyer's original equation which accounts for a single depopulating state. $^{22,23}$ Including a second state yields the following equation (for derivation see the ESI†):

$$
\begin{aligned}
\ln (\phi)= & \ln \left(k_{\mathrm{r}}\right)-\ln \left[k_{\mathrm{r}}+k_{\mathrm{nr}}+k_{1} \exp \left(-\Delta E_{1} / R T\right)\right. \\
& \left.+k_{2} \exp \left(-\Delta E_{2} / R T\right)\right] .
\end{aligned}
$$

The rate constants $k_{\mathrm{r}}$ and $k_{\mathrm{nr}}$ describe the radiative and non-radiative decays $\left({ }^{3} \mathrm{MLCT} \rightarrow{ }^{1} \mathrm{GS}\right), \Delta E_{1}$ corresponds to the activation barrier for surface crossing from the ${ }^{3}$ MLCT to the ${ }^{3} \mathrm{MC}$ state $\left(\Delta E_{1}=\Delta G_{1}^{\ddagger}\right)$ and $k_{1}$ is the rate constant for this surface crossing at infinite temperature as shown by Meyer. ${ }^{22}$

An analogous equation was previously used by Balzani and coworkers to describe the photodynamics of complexes of the $\left[\mathrm{Ru}(\mathrm{bpy})_{3}\right]^{2+}$ family. ${ }^{79,80}$ In these cases, $\Delta E_{1}$ corresponds to the barrier for the thermally activated ${ }^{3} \mathrm{MLCT} \rightarrow{ }^{3} \mathrm{MC}$ surface crossing while $\Delta E_{2}$ (typically $<1 \mathrm{~kJ} \mathrm{~mol}^{-1}$ ) is interpreted as the energy separation between multiple close-lying ${ }^{3} \mathrm{MLCT}$ states split by spin-orbit coupling. ${ }^{80-82}$

In the present study, $\Delta E_{2}$ can be interpreted either as the energy difference $\Delta G_{0}$ of the ${ }^{3} \mathrm{MLCT}$ and ${ }^{3} \mathrm{LL}$ 'CT states in thermal equilibrium or the activation barrier $\Delta G_{2}^{\ddagger}$ for the surface crossing from the ${ }^{3}$ MLCT to the ${ }^{3}$ LL'CT state (see the ESI $\dagger$ for in-depth elaboration). This depends on the relative rate constants for the reverse internal conversion ${ }^{3} \mathrm{LL}$ 'CT $\rightarrow$ ${ }^{3} \mathrm{MLCT}$ and the non-radiative intersystem crossing (ISC) to the ground state $\left({ }^{3} \mathrm{LL}\right.$ 'CT $\left.\rightarrow{ }^{1} \mathrm{GS}\right)$. Upon cooling of solutions of all four mononuclear complexes, even complexes $\mathbf{1}^{+}$and $2^{+}$, in which the emissive ${ }^{3}$ MLCT state is not the triplet ground state, the emission intensity increases. This corroborates that ${ }^{3}$ MLCT and ${ }^{3}$ LL'CT cannot be in thermal equilibrium at least in complexes $\mathbf{1}^{+}$and $2^{+}$. For complexes $3^{+}$and $4^{+}$, this conclusion cannot be drawn purely based on the temperature dependence of the emission quantum yield, since both, the energy difference of the ${ }^{3} \mathrm{MLCT}$ and ${ }^{3} \mathrm{LL}$ 'CT states and the activation barrier $\Delta G_{2}^{\ddagger}$, are positive. Based on the DFT calculated energies of the activation barriers for the ${ }^{3} \mathrm{MLCT}-{ }^{3} \mathrm{LL} \mathrm{CT}^{\prime}$ surface crossing and the experimentally determined $\Delta E_{2}$ values (vide infra), however, it is plausible, that also for complexes $3^{+}$and $4^{+}$, the surface crossing into the ${ }^{3} \mathrm{LL}$ CT state is irreversible and followed by rapid relaxation into the singlet ground state. Consequently, $\Delta E_{2}$ is identified in analogy to $\Delta E_{1}=\Delta G_{1}^{\ddagger}$ as the activation barrier $\Delta G_{2}^{*}$ for the thermal depopulation of the ${ }^{3}$ MLCT via the ${ }^{3} \mathrm{LL}^{\prime} \mathrm{CT}$ states.

Based on the very similar $0-0$ emission energies which should give similar rate constants for the non-radiative decay $\left({ }^{3} \mathrm{MLCT} \rightarrow{ }^{1} \mathrm{GS}\right)$, the large differences in the phosphorescence quantum yields of the four complexes $\mathbf{1}^{+}-\mathbf{4}^{+}$are quite unexpected (Table 2). ${ }^{83-85}$ Yet, combining the $\ln (\phi)$ vs. $T^{-1}$ plots with the relative energies of the involved states as determined by DFT provides an explanation. For complexes $3^{+}$and $4^{+}$the 
relatively high quantum yield is associated with the emissive ${ }^{3}$ MLCT state being the triplet ground state. For $\mathbf{1}^{+}$and $2^{+}$on the other hand, the non-emissive ${ }^{3} \mathrm{LL}^{\prime} \mathrm{CT}$ state becomes the triplet ground state giving rise to a deactivation pathway with a potentially very low activation barrier $\Delta G_{1}^{\ddagger}$. Due to the small experimentally accessible temperature range, the fit using the biexponential equation given above is overparametrized. Consequently, quantitative results have to be considered very carefully. For $\mathbf{1}^{+}$, activation barriers of $\Delta G_{1}^{\ddagger}=21.7$ and $\Delta G_{2}^{\ddagger}=$ $2.1 \mathrm{~kJ} \mathrm{~mol}^{-1}$ are obtained from the fit, while for $3^{+}$, the activation barriers are $\Delta G_{1}^{\ddagger}=23.1$ and $\Delta G_{2}^{\ddagger}=6.2 \mathrm{~kJ} \mathrm{~mol}^{-1}$. Based on the calculated energies of the various triplet states (Fig. 7), it is reasonable to assume that the higher activation barriers $\Delta G_{1}^{\ddagger}$ of $>20 \mathrm{~kJ} \mathrm{~mol}^{-1}$ are associated with the deactivation via the ${ }^{3} \mathrm{MC}$ state (vide infra). $\Delta G_{2}^{\ddagger}$ is very similar for both the NHR- and COOR-substituted complex types, corroborating that the substitution pattern at the cyclometalating ligand only has a marginal effect on the ligand field splitting in the $[\mathrm{Ru}(\mathrm{dpb}-$ $\mathrm{R})(\text { tpy) }]^{+}$type of complexes. The second activation barrier $\Delta G_{2}^{\ddagger}$ of $\mathbf{1}^{+}$is only one third of that of $3^{+}$. Hence, thermal deactivation via ${ }^{3} \mathrm{LL}$ 'CT states is significantly accelerated by the presence of an electron donating substituent at the dpb ligand explaining the substantially lower quantum yield of the former. Substituents at the tpy ligand on the other hand are expected to influence both activation barriers but especially $\Delta G_{1}^{\ddagger}$ between the ${ }^{3} \mathrm{MLCT}$ and ${ }^{3} \mathrm{MC}$ states since the substituents at the tpy ligand significantly impact the ${ }^{3}$ MLCT energy.

To gain a better understanding of the excited state processes, we performed DFT based geometry optimizations to find the transition states connecting the ${ }^{3} \mathrm{MLCT}$ and the ${ }^{3} \mathrm{MC}$ states on one side and the ${ }^{3} \mathrm{MLCT}$ and ${ }^{3} \mathrm{LL}$ 'CT states on the other. All four transition states could be localized successfully and their nature confirmed by the presence of a single negative vibrational frequency representing the reaction coordinate of the respective transition (Fig. 9). Subsequent spin density calculations further confirmed the nature of the localized states as the desired transition states. For both complexes, $\mathbf{1}^{+}$and $\mathbf{3}^{+}$, the spin density of the ${ }^{3} \mathrm{MLCT}-{ }^{3} \mathrm{LL}$ 'CT transition state shows contributions of both ligands and, predominantly, the metal center. Remarkably, the spin carrying orbital at the metal center neither corresponds to the $\mathrm{d}_{x y}$ orbital as in the ${ }^{3}$ MLCT state nor to the $\mathrm{d}_{y z}$ orbital as in the ${ }^{3} \mathrm{LL} \mathrm{LT}^{\prime} \mathrm{C}$ state but is a linear combination of both. This further underlines the transition state character of the localized state. Similarly, the ${ }^{3}$ MLCT $-{ }^{3} \mathrm{MC}$ transition states of $\mathbf{1}^{+}$and $3^{+}$show a substantial amount of spin density at the metal center (1.46 electrons based on Mulliken's spin population analysis). But instead of the nitrogen lone pairs, a tpy $\pi^{*}$-orbital (LUMO of $\mathbf{1}^{+}$and $\mathbf{3}^{+}$) contributes to this transition state. The DFT calculated transition state energies $\Delta G_{1}^{\ddagger}$ (DFT) and $\Delta G_{2}^{\ddagger}$ (DFT) and $G_{1}^{\ddagger}$ (exp.) and $\Delta G_{2}^{\ddagger}$ (exp.) extracted from the fits of the $\ln (\phi) v s . T^{-1}$ plots show remarkable agreement with deviation as small as $\pm 2 \mathrm{~kJ} \mathrm{~mol}^{-1}$. This suggests that despite the narrow temperature range of the VT measurement and their very low quantum yields and short excited state lifetimes, a very reasonable
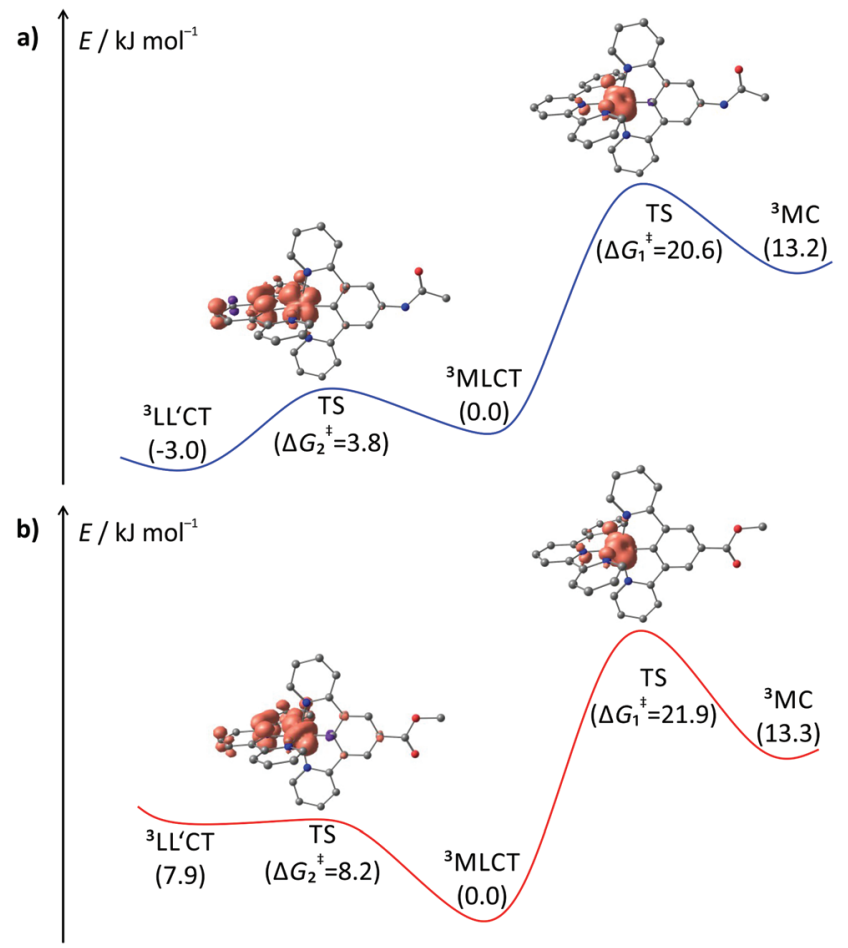

Fig. 9 Profile of the triplet hypersurface of (a) $1^{+}$and (b) $3^{+}$obtained from DFT calculations (B3LYP, def2-SV(P), ZORA, COSMO (acetonitrile)). Gibbs free energies are given in $\mathrm{kJ} \mathrm{mol}^{-1}$ relative to the emissive ${ }^{3} \mathrm{MLCT}$ state $\left(G_{\mathrm{MLCT}}=0 \mathrm{~kJ} \mathrm{~mol}^{-1}\right)$. Spin densities of the transition states (TS) are given at a contour value of 0.01 . Hydrogen atoms are omitted for clarity.

description of the excited state deactivation processes can be obtained for these cyclometalated complexes.

In summary, dpb ligands in bis(tridentate)ruthenium(II) complexes indeed induce high-energy ${ }^{3} \mathrm{MC}$ states, but give rise to low-energy ${ }^{3} \mathrm{LL}$ CT states. As for both states, emission is symmetry-forbidden, both contribute to the rapid excited state deactivation observed for these types of complexes. The combination of two $[\mathrm{Ru}(\mathrm{dpb})(\mathrm{tpy})]^{+}$emitters is discussed in the next chapter.

\section{Emission spectroscopy and triplet excited states of complex $6\left(\mathrm{PF}_{6}\right)_{2}$}

For the dinuclear complex $6^{2+}$, a broadened emission spectrum is obtained at room temperature compared to the formally constituting mononuclear complexes $\mathbf{1}^{+}$and $3^{+}$(Fig. 10). Additionally, the position of the emission maximum is dependent on the excitation wavelengths and shifts from $756 \mathrm{~nm}$ upon excitation at $480 \mathrm{~nm}$ to $772 \mathrm{~nm}$ when being irradiated at $560 \mathrm{~nm}$ (Fig. 10 and Table 2). Measurement at $155 \mathrm{~K}$ in butyronitrile yields substantially sharpened emission spectra with an emission maximum at $746 \mathrm{~nm}$ and a pronounced shoulder at $800 \mathrm{~nm}$. The intensity of this shoulder increases upon increasing the excitation wavelength from 480 to $560 \mathrm{~nm}$. The blueshift of the emission maximum $\left(180 \mathrm{~cm}^{-1}\right)$ upon freezing the butyronitrile solution of $6^{2+}$ is much smaller than that of all mononuclear complexes under study. 


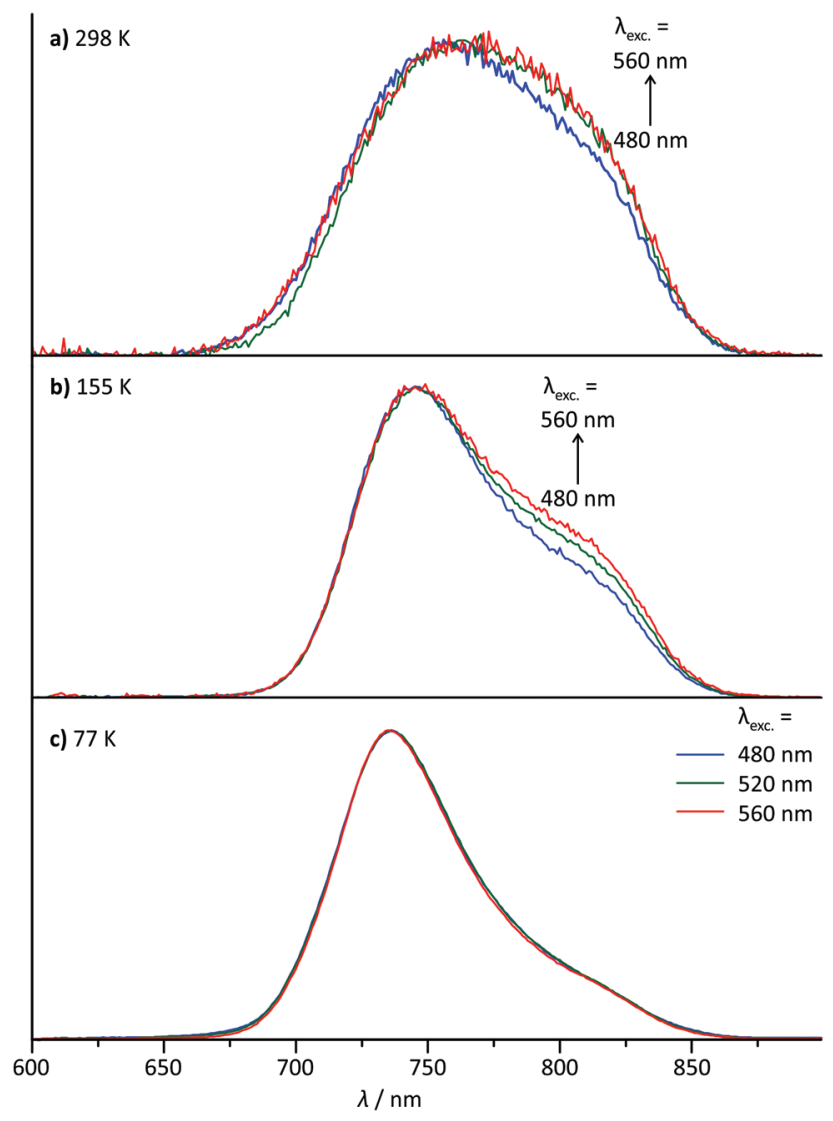

Fig. 10 Normalized steady-state emission spectra of $6\left(\mathrm{PF}_{6}\right)_{2}$ at varying excitation wavelengths (a) at room temperature in degassed acetonitrile solution, (b) at $155 \mathrm{~K}$ in liquid butyronitrile solution and (c) at $77 \mathrm{~K}$ in a frozen butyronitrile matrix.

A wavelength dependence of the emission maximum from the excitation energy is very atypical for polypyridineruthenium(II) complexes. We ascribe this behaviour to two independent emission processes in solution involving the two complex subunits of $6^{2+}$. In fact, similar dual emission processes have previously been invoked to explain the emission wavelength dependence from the excitation energy. ${ }^{86-89}$ Unfortunately, attempts to measure the excited state lifetimes by timecorrelated single photon counting failed in this case due to the very rapid excited state decay of $\mathbf{6}^{2+}$. Hence, no evidence for a biexponential character of the excited state decay, which would support the presence of a dual emission mechanism, could be obtained.

However, a reasonable explanation for the dual emission of $6^{2+}$ can be given based on its absorption characteristics. As shown above, the visible range of the absorption spectrum of $6^{2+}$ is composed of ${ }^{1}$ MLCT excitations localized on one of the two complex halves. Upon intersystem crossing and vibrational relaxation, $\mathrm{d}_{x z}(\mathrm{Ru}) \rightarrow$ tpy ${ }^{3} \mathrm{MLCT}$ states are populated. Two such triplet excited states are conceivable, namely ${ }^{3}\left[\mathrm{tpy}^{-}\right)$ $\left.\mathrm{Ru}^{\mathrm{III}}(\mathrm{dpb}-\mathrm{NHCO}-\mathrm{dpb}) \mathrm{Ru}^{\mathrm{II}}(\mathrm{tpy})\right]^{2+}$ and ${ }^{3}\left[\left(\right.\right.$ tpy)Ru ${ }^{\mathrm{II}}$ (dpb-NHCO$\left.\mathrm{dpb}) \mathrm{Ru}^{\mathrm{III}}\left(\mathrm{tpy}^{-}\right)\right]^{2+}$, with the triplet spin density localized on opposing [Ru(tpy)] fragments (ESI, Fig. S24†). Via double electron transfer from $\mathrm{Ru}^{\mathrm{II}}$ to $\mathrm{Ru}^{\mathrm{III}}$ and from tpy ${ }^{-}$to tpy (Dexter energy transfer), these states could interconvert. ${ }^{90,91}$ Apparently, due to the large distance between the two [Ru(tpy)] moieties $\left(r_{\mathrm{RuRu}}=13 \AA, r_{\text {tpy,tpy }} \approx 20 \AA\right)$, Dexter energy transfer, whose rate constant decays exponentially with distance, is rather slow between the complex subunits. All other radiative and non-radiative relaxation pathways of triplet $6^{2+}$ are extremely fast (below $1 \mathrm{~ns}$ as evidenced from time-resolved emission spectroscopy). Consequently, in fluid solution, emission occurs faster than thermal equilibration between the two emissive ${ }^{3}$ MLCT states. If equilibration was faster than emission, the ${ }^{3}\left[\left(\text { tpy }^{-}\right) \mathrm{Ru}^{\mathrm{III}}(\mathrm{dpb}-\mathrm{NHCO}-\mathrm{dpb}) \mathrm{Ru}^{\mathrm{II}}(\mathrm{tpy})\right]^{2+}$ state would be favoured over ${ }^{3}\left[(\text { tpy }) \mathrm{Ru}^{\mathrm{II}}(\mathrm{dpb}-\mathrm{NHCO}-\mathrm{dpb}) \mathrm{Ru}^{\mathrm{III}}\left(\mathrm{tpy}^{-}\right)\right]^{2+}$ thermodynamically and would yield single emission at around $800 \mathrm{~nm}$, but this is not observed.

Given that the two ${ }^{3}$ MLCT states are not in thermal equilibrium, it should be possible to selectively populate one or the other excited state by irradiation into one of the two complex subunits. Since in the absorption spectrum of $6^{2+}$ the absorption bands of the two fragments [(tpy)Ru(dpb-NHR)] and [(ROC-dpb)Ru(tpy)] overlap substantially, it is not possible to excite them with $100 \%$ selectivity (Fig. 4). But by changing the excitation wavelength it is possible to gradually tune the ratio at which the two building blocks are excited. The difference spectrum of the two mononuclear complexes $\mathbf{1}^{+}$and $3^{+}$carrying similar functional groups as the two subunits of $6^{2+}$ (Fig. 4) gives an idea where a maximum difference of absorption can be expected between the $\mathrm{NH}^{-}$and CO-substituted $[\mathrm{Ru}(\mathrm{dpb})(\mathrm{tpy})]^{+}$complex subunits. This difference spectrum reveals a maximized and minimized absorption of the CORsubstituted complex at around 480 and $560 \mathrm{~nm}$, respectively. This is in excellent agreement with the above mentioned minimum and maximum of the shoulder at $800 \mathrm{~nm}$ in the emission spectrum of $6^{2+}$ at $155 \mathrm{~K}$. Additionally, the difference spectrum of the emission spectra recorded at $155 \mathrm{~K}$ with $\lambda_{\text {exc }}=$ 480 and $560 \mathrm{~nm}$ reveals a band with a maximum at $800 \mathrm{~nm}$ (ESI, Fig. S25 $\dagger$ ) that resembles the emission band of $\mathbf{1}^{+}$at that temperature (Fig. 6b). These observations strongly support that dual emission occurs from two uncoupled ${ }^{3}$ MLCT excited states of the dinuclear complex $6^{2+}$ in solution.

The origin of this dual emission process is markedly different than that observed for the structurally similar amidebridged dinuclear complex [(EtOOC-tpy)Ru(tpy-NHCO-tpy) $\mathrm{Ru}(\mathrm{tpy}-\mathrm{NHCOMe})]^{4+}{ }^{55}$ In the latter, the involved emissive states are sufficiently long-lived and at a significantly shorter distance to allow for thermal equilibration prior to emission. Since the emissive states [(EtOOC-tpy)Ru ${ }^{\mathrm{II}}\left(\right.$ tpy-NHCO-tpy $\left.{ }^{-}\right)$ $\mathrm{Ru}^{\mathrm{III}}($ tpy-NHCOMe $\left.)\right]^{4+}$ and $\left[\left(\right.\right.$ EtOOC-tpy) $\mathrm{Ru}^{\mathrm{III}}\left(\right.$ tpy-NHCO-tpy $\left.^{-}\right)$ $\mathrm{Ru}^{\mathrm{II}}($ tpy-NHCOMe $\left.)\right]^{4+}$ are very similar in energy, occupation between the two is Boltzmann distributed leading to dual emission at room temperature.

Interestingly, upon freezing of the butyronitrile solution of $\mathbf{6}^{2+}$, single emission is observed arising from the NHR-substituted subunit as judged from the position of the emission maximum as well as the independence of the emission band shape from the excitation wavelength (Fig. 10c). This loss of 
dual emission can be traced back to the change in the rate constants involved with the excited state decay. Upon freezing the solvent matrix around a given luminescent dye, both nonradiative vibrational relaxation and emissive decay are slowed down substantially. This is because they are typically accompanied by geometrical rearrangements of the dye and the environment and such rearrangements are much more difficult in a rigid solvent cage. The rate for intramolecular Dexter energy transfer on the other hand is not significantly diminished upon freezing of the solvent. ${ }^{92,93}$ Consequently, in frozen solution, the two ${ }^{3}$ MLCT states of $6^{2+}$ equilibrate thermally prior to emission from the lower-energy ${ }^{3}\left[\right.$ tpy $\left.^{-}\right)$ $\left.\mathrm{Ru}^{\mathrm{III}}(\mathrm{dpb}-\mathrm{NHCO}-\mathrm{dpb}) \mathrm{Ru}^{\mathrm{II}}(\mathrm{tpy})\right]^{2+}$ state following Kasha's rule. ${ }^{94}$

\section{Experimental}

\section{General procedures}

Chemicals were obtained from commercial suppliers and used without further purification. Air- or moisture-sensitive reactions were performed in dried glassware under an inert gas atmosphere (argon, quality 4.6). Acetonitrile was refluxed over $\mathrm{CaH}_{2}$ and distilled under argon prior to use. The ligands $N$-acetyl-3,5-dipyrid-2'-ylaniline $\mathbf{L 1}^{40}$ and ethyl 3,5-dipyrid-2'ylbenzoate $\mathbf{L} 2^{40}$ as well as $\mathrm{RuCl}_{3}$ (tpy) ${ }^{95}$ were synthesized following the literature-known procedures. Infrared spectra were recorded on a Varian Excalibur Series 3100 FT-IR spectrometer using $\mathrm{KBr}$ disks. IR absorption band intensities are classified as s (strong), m (medium) and w (weak). UV/Vis spectra were recorded on a Varian Cary 5000 spectrometer in $1 \mathrm{~cm}$ cuvettes. Emission spectra were recorded on a Varian Cary Eclipse spectrometer. Quantum yields were determined by comparing the areas under the emission spectra on an energy scale recorded for solutions of the samples and a reference with matching absorbances $\left(\phi\left(\left[\mathrm{Ru}(\text { bipy })_{3}\right] \mathrm{Cl}_{2}\right)=0.094\right.$ in deaerated $\mathrm{MeCN}){ }^{21}$ Experimental uncertainty is estimated to be $15 \%$. Low temperature emission spectra were recorded using an Oxford Instruments Optistat DN cryostat with cooling by liquid $\mathrm{N}_{2}$. $\mathrm{ESI}^{+}$and high resolution $\mathrm{ESI}^{+}$mass spectra were recorded on a Micromass QTof Ultima API mass spectrometer with analyte solutions in acetonitrile. Elemental analyses were performed in the microanalytical laboratory of the Chemical Institutes of the University of Mainz. NMR spectra were obtained with a Bruker Avance II 400 spectrometer at $400.31\left({ }^{1} \mathrm{H}\right)$ and $100.66\left({ }^{13} \mathrm{C}\right)$ at $25{ }^{\circ} \mathrm{C}$. Chemical shifts $\delta[\mathrm{ppm}]$ are reported with respect to residual solvent signals as internal standards $\left({ }^{1} \mathrm{H},{ }^{13} \mathrm{C}\right): \mathrm{CD}_{3} \mathrm{CN} \delta\left({ }^{1} \mathrm{H}\right)=1.94 \mathrm{ppm}, \delta\left({ }^{13} \mathrm{C}\right)=1.32$ and 118.26 ppm. $^{96}$ Electrochemical experiments were performed with a BioLogic SP-50 voltammetric analyzer at a sample concentration of $10^{-3} \mathrm{~mol} \mathrm{l}^{-1}$ using platinum wire as working and counter electrodes and a $0.01 \mathrm{~mol} \mathrm{l}{ }^{-1} \mathrm{Ag} / \mathrm{AgNO}_{3}$ reference electrode. Measurements were carried out at a scan rate of $100 \mathrm{mV}$ $\mathrm{s}^{-1}$ for cyclic voltammetry experiments and at $10 \mathrm{mV} \mathrm{s}^{-1}$ for square-wave voltammetry experiments using $0.1 \mathrm{~mol} \mathrm{l}^{-1}$ $\left[n \mathrm{Bu}_{4} \mathrm{~N}\right]\left[\mathrm{PF}_{6}\right]$ as the supporting electrolyte in acetonitrile. Potentials are given relative to the ferrocene/ferrocenium couple $\left(0.40 \mathrm{~V}\right.$ vs. SCE, $E_{1 / 2}=0.09 \pm 5 \mathrm{mV}$ under the given conditions). ${ }^{72}$

\section{Density functional theory calculations}

DFT calculations were carried out using the ORCA program package (version 3.0.2). ${ }^{97}$ Tight convergence criteria were chosen for all calculations (keywords TightSCF and TightOpt, convergence criteria for the SCF part: energy change $1.0 \times 10^{-8}$ $\mathrm{E}_{\mathrm{h}}$, 1-El. energy change $1.0 \times 10^{-5} \mathrm{E}_{\mathrm{h}}$, orbital gradient $1.0 \times$ $10^{-5}$, orbital rotation angle $1.0 \times 10^{-5}$, DIIS error $5.0 \times 10^{-7}$; for geometry optimizations: energy change: $1.0 \times 10^{-6} \mathrm{E}_{\mathrm{h}}$, max. gradient $1.0 \times 10^{-4} \mathrm{E}_{\mathrm{h}}$ per bohr, RMS gradient $3.0 \times 10^{-5} \mathrm{E}_{\mathrm{h}}$ per bohr, max. displacement $1.0 \times 10^{-3}$ bohr, RMS displacement $6.0 \times 10^{-4}$ bohr). All calculations employ the resolution of identity (Split-RI-J) approach for the coulomb term in combination with the chain-of-spheres approximation for the exchange term (COSX). ${ }^{98,99}$ All calculations were performed using the hybrid functional B3LYP ${ }^{63}$ in combination with Ahlrichs' split-valence double- $\xi$ basis set def2-SV(P) which comprises polarization functions for all non-hydrogen atoms. ${ }^{64,65}$ Relativistic effects were calculated at the zeroth order regular approximation (ZORA) niveau. ${ }^{67}$ The ZORA keyword automatically invokes relativistically adjusted basis sets. ${ }^{100}$ To account for solvent effects, a conductor-like screening model (COSMO) modelling acetonitrile was used in all calculations. ${ }^{68}$ TD-DFT calculations with at least 50 vertical transitions were carried out based on the def2-SV(P) optimized geometry of the respective complex. Explicit counterions and/or solvent molecules were not taken into account in all cases. To reduce the computational cost, methyl instead of ethyl groups at the ester moiety were used throughout all calculations.

Synthesis of $\left[\mathrm{Ru}\left(\mathrm{dpb}-\mathrm{NHCOCH}_{3}\right)\left(\mathrm{tpy}_{\mathrm{p}}\right)\right]\left(\mathrm{PF}_{\mathbf{6}}\right) \quad \mathbf{1}\left(\mathrm{PF}_{6}\right)$. $\mathrm{RuCl}_{3}$ (tpy) (250 mg, $0.567 \mathrm{mmol}, 1$ eq.) and $\mathrm{AgBF}_{4}(320 \mathrm{mg}$, $1.64 \mathrm{mmol}, 2.9 \mathrm{eq}$.) were dissolved in dry acetone $(20 \mathrm{ml})$ and heated to reflux for $2 \mathrm{~h}$ in the dark. The mixture was left to stand for $1 \mathrm{~h}$ and filtered through a syringe filter before removing the solvent under reduced pressure. The dark residue was dissolved in $n \mathrm{BuOH}(20 \mathrm{ml})$ and $N$-acetyl-3,5-dipyrid-2'-ylaniline $\mathbf{L 1}$ (197 mg, $0.680 \mathrm{mmol}, 1.2$ eq.) was added. The resulting mixture was heated to reflux for $16 \mathrm{~h}$ to give a dark purple solution. After the removal of the solvent under reduced pressure, the residue was dissolved in a minimal amount of acetonitrile $(5 \mathrm{ml})$. Upon addition of a solution of $\mathrm{NH}_{4} \mathrm{PF}_{6}$ (220 mg, $1.35 \mathrm{mmol}, 2.4$ eq.) in water $(1 \mathrm{ml})$ followed by slow addition of more water $(80 \mathrm{ml})$, a black solid precipitated which was filtered off. Column chromatography on silica gel $\left(\mathrm{CHCl}_{3}: \mathrm{MeOH}=7: 1\right)$ afforded $\left[\mathrm{Ru}\left(\mathrm{dpb}-\mathrm{NHCOCH}_{3}\right)(\mathrm{tpy})\right]\left(\mathrm{PF}_{6}\right)$ $\mathbf{1}\left(\mathrm{PF}_{6}\right)$ as a dark purple solid. Yield: $175 \mathrm{mg}(0.228 \mathrm{mmol}$, $40 \%$ ). Anal. Calc. for $\mathrm{C}_{33} \mathrm{H}_{25} \mathrm{~F}_{6} \mathrm{~N}_{6} \mathrm{OPRu}(767.6) \cdot \mathrm{H}_{2} \mathrm{O}$ : C, 50.45;

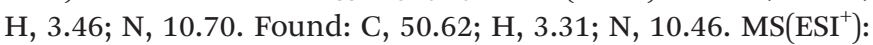
$m / z(\%)=623.1(100)\left[\mathrm{M}-\mathrm{PF}_{6}\right]^{+}$. HR-MS(ESI $\left.{ }^{+}, m / z\right)$ : Calcd for $\mathrm{C}_{33} \mathrm{H}_{25} \mathrm{~N}_{6} \mathrm{ORu}\left[\mathrm{M}-\mathrm{PF}_{6}\right]^{+}$: 617.1166; Found: 617.1177. ${ }^{1} \mathrm{H} \mathrm{NMR}$ $\left(\mathrm{CD}_{3} \mathrm{CN}\right): \delta[\mathrm{ppm}]=8.73\left(\mathrm{~d},{ }^{3} J_{\mathrm{HH}}=8 \mathrm{~Hz}, 2 \mathrm{H}, \mathrm{H}^{2 \mathrm{~A}}\right), 8.62(\mathrm{~s}, 1 \mathrm{H}$, $\mathrm{NH}), 8.44-8.35\left(\mathrm{~m}, 4 \mathrm{H}, \mathrm{H}^{2 \mathrm{~B}}, \mathrm{H}^{5 \mathrm{~A}}\right), 8.24\left(\mathrm{t},{ }^{3} J_{\mathrm{HH}}=8 \mathrm{~Hz}, 1 \mathrm{H}\right.$, $\left.\mathrm{H}^{1 \mathrm{~A}}\right), 8.05\left(\mathrm{~d},{ }^{3} J_{\mathrm{HH}}=8 \mathrm{~Hz}, 2 \mathrm{H}, \mathrm{H}^{5 \mathrm{~B}}\right), 7.67\left(\mathrm{dt},{ }^{3} J_{\mathrm{HH}}=8 \mathrm{~Hz}\right.$, $\left.{ }^{4} J_{\mathrm{HH}}=1 \mathrm{~Hz}, 2 \mathrm{H}, \mathrm{H}^{6 \mathrm{~A}}\right), 7.59\left(\mathrm{dt},{ }^{3} J_{\mathrm{HH}}=8 \mathrm{~Hz},{ }^{4} J_{\mathrm{HH}}=1 \mathrm{~Hz}, 2 \mathrm{H}\right.$, 
$\left.\mathrm{H}^{6 \mathrm{~B}}\right), 7.11\left(\mathrm{~d},{ }^{3} J_{\mathrm{HH}}=5 \mathrm{~Hz}, 2 \mathrm{H}, \mathrm{H}^{8 \mathrm{~A}}\right), 7.01\left(\mathrm{~d},{ }^{3} J_{\mathrm{HH}}=5 \mathrm{~Hz}, 2 \mathrm{H}\right.$, $\left.\mathrm{H}^{8 \mathrm{~B}}\right), 6.94\left(\mathrm{~m}, 2 \mathrm{H}, \mathrm{H}^{7 \mathrm{~A}}\right), 6.64\left(\mathrm{~m}, 2 \mathrm{H}, \mathrm{H}^{7 \mathrm{~B}}\right), 2.23\left(\mathrm{~s}, 3 \mathrm{H}, \mathrm{H}^{11}\right)$. ${ }^{13} \mathrm{C}\left\{{ }^{1} \mathrm{H}\right\}$ NMR $\left(\mathrm{CD}_{3} \mathrm{CN}\right): \delta[\mathrm{ppm}]=217.2\left(\mathrm{C}^{9 \mathrm{~B}}\right), 169.6\left(\mathrm{C}^{10}\right)$, $169.4\left(\mathrm{C}^{4 \mathrm{~B}}\right), 160.1\left(\mathrm{C}^{4 \mathrm{~A}}\right), 155.3\left(\mathrm{C}^{8 \mathrm{~A}}\right), 154.0\left(\mathrm{C}^{3 \mathrm{~A}}\right), 152.9\left(\mathrm{C}^{8 \mathrm{~B}}\right)$, $142.5\left(\mathrm{C}^{3 \mathrm{~B}}\right), 136.4\left(\mathrm{C}^{6 \mathrm{~B}}\right), 135.9\left(\mathrm{C}^{6 \mathrm{~A}}\right), 133.6\left(\mathrm{C}^{1 \mathrm{~B}}\right), 132.7\left(\mathrm{C}^{1 \mathrm{~A}}\right)$, $127.2\left(\mathrm{C}^{7 \mathrm{~A}}\right), 124.4\left(\mathrm{C}^{5 \mathrm{~A}}\right), 123.2\left(\mathrm{C}^{2 \mathrm{~A}}\right), 122.5\left(\mathrm{C}^{7 \mathrm{~B}}\right), 120.6\left(\mathrm{C}^{5 \mathrm{~B}}\right)$, $117.8\left(\mathrm{C}^{2 \mathrm{~A}}\right), 24.3\left(\mathrm{C}^{11}\right)$. IR (KBr disk): $\tilde{\nu}\left[\mathrm{cm}^{-1}\right]=3230(\mathrm{~m}, \mathrm{~N}-\mathrm{H}$ amide), 1650 (s, $\mathrm{C}=\mathrm{O}$ amide), $1600(\mathrm{~m}, \mathrm{C}=\mathrm{C}$ ), 1520 (w, amide II), 843 (s, P-F).

Synthesis of $\left[\mathbf{R u}\left(\mathbf{d p b}_{-} \mathbf{N H}_{2}\right)\left(\mathrm{tpy}_{\mathrm{p}}\right)\right]\left(\mathbf{P F}_{6}\right) \quad 2\left(\mathbf{P F}_{6}\right) \cdot[\mathrm{Ru}(\mathrm{dpb}-$ $\left.\left.\mathrm{NHCOCH}_{3}\right)(\mathrm{tpy})\right]\left(\mathrm{PF}_{6}\right) \mathbf{1}\left(\mathrm{PF}_{6}\right)$ (113 $\mathrm{mg}, 0.147 \mathrm{mmol}$ ) was added to a mixture of water $(20 \mathrm{ml})$, methanol $(20 \mathrm{ml})$, hydrazine monohydrate $(1 \mathrm{ml})$ and sodium hydroxide $(1 \mathrm{~g})$ and heated to reflux for $16 \mathrm{~h}$. After removal of the solvent under reduced pressure, the dark residue was dissolved in a minimal amount of acetonitrile $(5 \mathrm{ml})$ followed by addition of a solution of $\mathrm{NH}_{4} \mathrm{PF}_{6}$ (153 mg, $0.939 \mathrm{mmol}, 6.75$ eq.) in water $(80 \mathrm{ml})$. The precipitate was filtered off and washed with water $(2 \times 5 \mathrm{ml})$ and diethyl ether $(2 \times 15 \mathrm{ml})$ giving $\left[\mathrm{Ru}\left(\mathrm{dpb}-\mathrm{NH}_{2}\right)(\mathrm{tpy})\right]\left(\mathrm{PF}_{6}\right)$ $2\left(\mathrm{PF}_{6}\right)$ as a purple solid. Yield: $92 \mathrm{mg}(0.127 \mathrm{mmol}, 86 \%)$. Anal. Calc. for $\mathrm{C}_{31} \mathrm{H}_{23} \mathrm{~F}_{6} \mathrm{~N}_{6} \mathrm{PRu}(725.6) \cdot 0.5 \mathrm{H}_{2} \mathrm{O}: \mathrm{C}, 50.69 ; \mathrm{H}, 3.29 ; \mathrm{N}$, 11.58. Found: C, 50.82; H, 3.05; N, 11.34. $\left.\mathrm{MS} \mathrm{ESI}^{+}\right): m / z(\%)=$ 581.1 (100) $\left[\mathrm{M}-\mathrm{PF}_{6}\right]^{+}$. HR-MS(ESI $\left.{ }^{+}, \mathrm{m} / z\right)$ : Calcd for $\mathrm{C}_{31} \mathrm{H}_{23} \mathrm{~N}_{6} \mathrm{Ru}\left[\mathrm{M}-\mathrm{PF}_{6}\right]^{+}$: 575.1060; Found: 575.1071. ${ }^{1} \mathrm{H}$ NMR $\left(\mathrm{CD}_{3} \mathrm{CN}\right): \delta[\mathrm{ppm}]=8.72\left(\mathrm{~d},{ }^{3} J_{\mathrm{HH}}=8 \mathrm{~Hz}, 2 \mathrm{H}, \mathrm{H}^{2 \mathrm{~A}}\right), 8.40\left(\mathrm{~d},{ }^{3} J_{\mathrm{HH}}\right.$ $\left.=8 \mathrm{~Hz}, 2 \mathrm{H}, \mathrm{H}^{5 \mathrm{~A}}\right), 8.20\left(\mathrm{t},{ }^{3} J_{\mathrm{HH}}=8 \mathrm{~Hz}, 1 \mathrm{H}, \mathrm{H}^{1 \mathrm{~A}}\right), 8.00\left(\mathrm{~d},{ }^{3} J_{\mathrm{HH}}=\right.$ $\left.8 \mathrm{~Hz}, 2 \mathrm{H}, \mathrm{H}^{5 \mathrm{~B}}\right), 7.74\left(\mathrm{~s}, 2 \mathrm{H}, \mathrm{H}^{2 \mathrm{~B}}\right), 7.67\left(\mathrm{t},{ }^{3} J_{\mathrm{HH}}=8 \mathrm{~Hz}, 2 \mathrm{H}, \mathrm{H}^{6 \mathrm{~A}}\right)$, $7.56\left(\mathrm{t},{ }^{3} \mathrm{~J}_{\mathrm{HH}}=8 \mathrm{~Hz}, 2 \mathrm{H}, \mathrm{H}^{6 \mathrm{~B}}\right), 7.18\left(\mathrm{~d},{ }^{3} J_{\mathrm{HH}}=5 \mathrm{~Hz}, 2 \mathrm{H}, \mathrm{H}^{8 \mathrm{~A}}\right)$, $6.97\left(\mathrm{dd},{ }^{3} J_{\mathrm{HH}}=5 \mathrm{~Hz}, 8 \mathrm{~Hz}, 2 \mathrm{H}, \mathrm{H}^{7 \mathrm{~A}}\right), 6.93\left(\mathrm{~d},{ }^{3} J_{\mathrm{HH}}=5 \mathrm{~Hz}, 2 \mathrm{H}\right.$, $\left.\mathrm{H}^{8 \mathrm{~B}}\right), 6.58\left(\mathrm{dd},{ }^{3} J_{\mathrm{HH}}=5 \mathrm{~Hz}, 8 \mathrm{~Hz}, 2 \mathrm{H}, \mathrm{H}^{7 \mathrm{~B}}\right), 4.24\left(\mathrm{~s}, 2 \mathrm{H}, \mathrm{NH}_{2}\right)$. ${ }^{13} \mathrm{C}\left\{{ }^{1} \mathrm{H}\right\}$ NMR $\left(\mathrm{CD}_{3} \mathrm{CN}\right): \delta[\mathrm{ppm}]=208.9\left(\mathrm{C}^{9 \mathrm{~B}}\right), 169.9\left(\mathrm{C}^{94 \mathrm{~B}}\right)$, $160.3\left(\mathrm{C}^{4 \mathrm{~A}}\right), 155.2\left(\mathrm{C}^{8 \mathrm{~A}}\right), 154.3\left(\mathrm{C}^{3 \mathrm{~A}}\right), 152.8\left(\mathrm{C}^{8 \mathrm{~B}}\right), 143.6\left(\mathrm{C}^{1 \mathrm{~B}}\right)$, $142.6\left(\mathrm{C}^{3 \mathrm{~B}}\right), 136.2\left(\mathrm{C}^{6 \mathrm{~B}}\right), 135.5\left(\mathrm{C}^{6 \mathrm{~A}}\right), 132.0\left(\mathrm{C}^{1 \mathrm{~A}}\right), 127.2\left(\mathrm{C}^{7 \mathrm{~A}}\right)$, $124.2\left(\mathrm{C}^{5 \mathrm{~A}}\right), 123.2\left(\mathrm{C}^{2 \mathrm{~A}}\right), 122.0\left(\mathrm{C}^{7 \mathrm{~B}}\right), 120.4\left(\mathrm{C}^{5 \mathrm{~B}}\right), 113.0\left(\mathrm{C}^{2 \mathrm{~B}}\right)$. IR (KBr disk): $\tilde{\nu}\left[\mathrm{cm}^{-1}\right]=3420(\mathrm{~m}, \mathrm{~N}-\mathrm{H}$ amine $), 1600(\mathrm{~m}$, $\mathrm{C}=\mathrm{C}), 843$ (s, P-F).

Synthesis of $\left[\mathrm{Ru}\left(\mathrm{dpb}-\mathrm{COOC}_{2} \mathrm{H}_{5}\right)\left(\mathrm{tpy}^{\mathrm{a}}\right)\right]\left(\mathrm{PF}_{6}\right) \quad \mathbf{3}\left(\mathrm{PF}_{6}\right)$. $\left[\mathrm{RuCl}_{3}(\mathrm{tpy})\right]$ (250 mg, $0.567 \mathrm{mmol}, 1$ eq.) and $\mathrm{AgBF}_{4}(320 \mathrm{mg}$, $1.64 \mathrm{mmol}, 2.9 \mathrm{eq}$.) were dissolved in dry acetone $(20 \mathrm{ml})$ and heated to reflux for $2 \mathrm{~h}$ in the dark. The mixture was left to stand for $1 \mathrm{~h}$ and filtered through a syringe filter before removing the solvent under reduced pressure. The dark residue was dissolved in $n \mathrm{BuOH}(20 \mathrm{ml})$ and ethyl 3,5-dipyrid-2'-ylbenzoate L2 (207 mg, $0.680 \mathrm{mmol}, 1.2$ eq.) was added. The resulting mixture was heated to reflux for $16 \mathrm{~h}$ to give a dark purple solution. After removal of the solvent under reduced pressure, the residue was dissolved in a minimal amount of acetonitrile $(5 \mathrm{ml})$. Upon addition of a solution of $\mathrm{NH}_{4} \mathrm{PF}_{6}(220 \mathrm{mg}$, $1.35 \mathrm{mmol}, 2.4$ eq.) in water $(1 \mathrm{ml})$ followed by slow addition of more water $(80 \mathrm{ml})$, a dark red solid precipitated that was filtered off and washed with water $(2 \times 5 \mathrm{ml})$ and diethyl ether $(2 \times 15 \mathrm{ml})$. Column chromatography on silica gel $\left(\mathrm{CHCl}_{3}\right.$ : $\mathrm{MeOH}=7: 1)$ afforded $\left[\mathrm{Ru}\left(\mathrm{dpb}-\mathrm{COOC}_{2} \mathrm{H}_{5}\right)(\mathrm{tpy})\right]\left(\mathrm{PF}_{6}\right) 3\left(\mathrm{PF}_{6}\right)$ as a dark red solid. Yield: $229 \mathrm{mg}$ (0.293 mmol, 52\%). Anal. Calc. for $\mathrm{C}_{34} \mathrm{H}_{26} \mathrm{~F}_{6} \mathrm{~N}_{5} \mathrm{O}_{2} \mathrm{PRu}$ (782.6): C, 52.18; $\mathrm{H}, 3.35 ; \mathrm{N}, 8.95$.

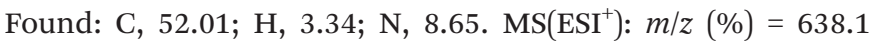

(100) $\left[\mathrm{M}-\mathrm{PF}_{6}\right]^{+}$. HR-MS(ESI $\left.{ }^{+}, m / z\right)$ : Calcd for $\mathrm{C}_{34} \mathrm{H}_{26} \mathrm{~N}_{5} \mathrm{O}_{2} \mathrm{Ru}$ $\left[\mathrm{M}-\mathrm{PF}_{6}\right]^{+}:$632.1162; Found: 632.1173. ${ }^{1} \mathrm{H}$ NMR $\left(\mathrm{CD}_{3} \mathrm{CN}\right)$ : $\delta[\mathrm{ppm}]=8.85\left(\mathrm{~s}, 2 \mathrm{H}, \mathrm{H}^{1 \mathrm{~B}}\right), 8.74\left(\mathrm{~d}, 2 \mathrm{H},{ }^{3} J_{\mathrm{HH}}=8 \mathrm{~Hz}, \mathrm{H}^{2 \mathrm{~A}}\right), 8.42$ $\left(\mathrm{d}, 2 \mathrm{H},{ }^{3} J_{\mathrm{HH}}=8 \mathrm{~Hz}, \mathrm{H}^{5 \mathrm{~A}}\right), 8.30\left(\mathrm{t}, 1 \mathrm{H},{ }^{3} J_{\mathrm{HH}}=8 \mathrm{~Hz}, \mathrm{H}^{1 \mathrm{~A}}\right), 8.27(\mathrm{~d}$, $\left.2 \mathrm{H},{ }^{3} \mathrm{~J}_{\mathrm{HH}}=8 \mathrm{~Hz}, \mathrm{H}^{5 \mathrm{~B}}\right), 7.74-7.56\left(\mathrm{~m}, 4 \mathrm{H}, \mathrm{H}^{6 \mathrm{~A}}, \mathrm{H}^{6 \mathrm{~B}}\right), 7.13-7.04$ $\left(\mathrm{m}, 4 \mathrm{H}, \mathrm{H}^{8 \mathrm{~A}}, \mathrm{H}^{8 \mathrm{~B}}\right), 6.91\left(\mathrm{t}, 2 \mathrm{H},{ }^{3} \mathrm{~J}_{\mathrm{HH}}=7 \mathrm{~Hz}, \mathrm{H}^{7 \mathrm{~A}}\right), 6.72(\mathrm{t}, 2 \mathrm{H}$, $\left.{ }^{3} J_{\mathrm{HH}}=7 \mathrm{~Hz}, \mathrm{H}^{7 \mathrm{~B}}\right), 4.52\left(\mathrm{q}, 2 \mathrm{H},{ }^{3} J_{\mathrm{HH}}=7 \mathrm{~Hz}, \mathrm{H}^{11}\right), 1.52(\mathrm{t}, 3 \mathrm{H}$, $\left.{ }^{3} J_{\mathrm{HH}}=7 \mathrm{~Hz}, \mathrm{H}^{12}\right) .{ }^{13} \mathrm{C}\left\{{ }^{1} \mathrm{H}\right\} \quad \mathrm{NMR}\left(\mathrm{CD}_{3} \mathrm{CN}\right): \delta[\mathrm{ppm}]=$ $232.8\left(\mathrm{C}^{9 \mathrm{~B}}\right), 168.9\left(\mathrm{C}^{4 \mathrm{~B}}\right), 168.6\left(\mathrm{C}^{10 \mathrm{~B}}\right), 159.8\left(\mathrm{C}^{4 \mathrm{~A}}\right), 155.4\left(\mathrm{C}^{8 \mathrm{~A}}\right)$, $153.5\left(\mathrm{C}^{3 \mathrm{~A}}\right), 152.8\left(\mathrm{C}^{8 \mathrm{~B}}\right), 143.1\left(\mathrm{C}^{3 \mathrm{~A}}\right), 136.7\left(\mathrm{C}^{6 \mathrm{~B}}\right), 136.4\left(\mathrm{C}^{6 \mathrm{~A}}\right)$, $133.8\left(\mathrm{C}^{1 \mathrm{~A}}\right), 127.3\left(\mathrm{C}^{7 \mathrm{~A}}\right), 124.6\left(\mathrm{C}^{2 \mathrm{~B}}\right), 124.5\left(\mathrm{C}^{6 \mathrm{~A}}\right), 123.3\left(\mathrm{C}^{2 \mathrm{~A}}\right)$, $123.0\left(\mathrm{C}^{7 \mathrm{~B}}\right), 120.9\left(\mathrm{C}^{1 \mathrm{~B}}\right), 61.5\left(\mathrm{C}^{11}\right), 14.9\left(\mathrm{C}^{12}\right)$. IR (KBr disk): $\tilde{\nu}\left[\mathrm{cm}^{-1}\right]=1695(\mathrm{~s}, \mathrm{C}=\mathrm{O}$ ester $), 1600,1582(\mathrm{~m}, \mathrm{C}=\mathrm{C}), 843$ (s, P-F).

Synthesis of $[\mathrm{Ru}(\mathrm{dpb}-\mathrm{COOH})(\mathrm{tpy})]\left(\mathrm{PF}_{6}\right) \quad \mathbf{4}\left(\mathrm{PF}_{\mathbf{6}}\right) \cdot[\mathrm{Ru}(\mathrm{dpb}-$ $\left.\left.\mathrm{COOC}_{2} \mathrm{H}_{5}\right)(\mathrm{tpy})\right]\left(\mathrm{PF}_{6}\right) 3\left(\mathrm{PF}_{6}\right)(154 \mathrm{mg}, 0.197 \mathrm{mmol})$ was added to a mixture of water $(20 \mathrm{ml})$, methanol $(20 \mathrm{ml})$, hydrazine monohydrate $(1 \mathrm{ml})$ and sodium hydroxide $(1 \mathrm{~g})$ and heated to reflux for $16 \mathrm{~h}$. After removal of the solvent under reduced pressure, the dark residue was dissolved in a minimal amount of acetonitrile $(5 \mathrm{ml})$ followed by slow addition of 1 mol per 1 aqueous $\mathrm{H}_{2} \mathrm{SO}_{4}$ to adjust the $\mathrm{pH}$ to 1 . Upon addition of a solution of $\mathrm{NH}_{4} \mathrm{PF}_{6}$ (145 mg, $0.890 \mathrm{mmol}, 4.5$ eq.) in water (40 ml) the product precipitated. The complex was filtered off and washed with water $(2 \times 5 \mathrm{ml})$ and diethyl ether $(2 \times 15 \mathrm{ml})$. Column chromatography on silica gel $\left(\mathrm{CHCl}_{3}: \mathrm{MeOH}=5: 1\right)$ afforded $[\mathrm{Ru}(\mathrm{dpb}-\mathrm{COOH})(\mathrm{tpy})]\left(\mathrm{PF}_{6}\right) \quad \mathbf{4}\left(\mathrm{PF}_{6}\right)$ as a dark red solid. Yield: $82 \mathrm{mg}(0.109 \mathrm{mmol}, 55 \%)$. Anal. Calc. for $\mathrm{C}_{32} \mathrm{H}_{22} \mathrm{~F}_{6} \mathrm{~N}_{5} \mathrm{O}_{2} \mathrm{PRu}$ (754.6): C, 50.93; H, 2.94; N, 9.28. Found: C, 50.64; H, 2.51; N, 9.42. $\operatorname{MS}\left(\mathrm{ESI}^{+}\right): m / z(\%)=610.1$ (100) $\left[\mathrm{M}-\mathrm{PF}_{6}\right]^{+}$. HR-MS(ESI $\left.{ }^{+}, \mathrm{m} / \mathrm{z}\right)$ : Calcd for $\mathrm{C}_{32} \mathrm{H}_{22} \mathrm{~N}_{5} \mathrm{O}_{2} \mathrm{Ru}$ $\left[\mathrm{M}-\mathrm{PF}_{6}\right]^{+}$: 604.0849; Found: 604.0873. ${ }^{1} \mathrm{H}$ NMR $\left(\mathrm{CD}_{3} \mathrm{CN}\right)$ : $\delta[\mathrm{ppm}]=8.85\left(\mathrm{~s}, 2 \mathrm{H}, \mathrm{H}^{2 \mathrm{~B}}\right), 8.74\left(\mathrm{~d},{ }^{3} J_{\mathrm{HH}}=8 \mathrm{~Hz}, 2 \mathrm{H}, \mathrm{H}^{2 \mathrm{~A}}\right), 8.42$ $\left(\mathrm{d},{ }^{3} J_{\mathrm{HH}}=8 \mathrm{~Hz}, 2 \mathrm{H}, \mathrm{H}^{5 \mathrm{~A}}\right), 8.33-8.24\left(\mathrm{~m}, 3 \mathrm{H}, \mathrm{H}^{1 \mathrm{~A}}, \mathrm{H}^{5 \mathrm{~B}}\right)$, 7.74-7.67 (m, 2H, $\left.\mathrm{H}^{6 \mathrm{~A}}\right), 7.67-7.60\left(\mathrm{~m}, 2 \mathrm{H}, \mathrm{H}^{6 \mathrm{~B}}\right), 7.13-7.05(\mathrm{~m}$, $4 \mathrm{H}, \mathrm{H}^{8 \mathrm{~A}}, \mathrm{H}^{8 \mathrm{~B}}$ ), $6.91\left(\mathrm{ddd},{ }^{3} J_{\mathrm{HH}}=7 \mathrm{~Hz}, 6 \mathrm{~Hz},{ }^{4} J_{\mathrm{HH}}=1 \mathrm{~Hz}, 2 \mathrm{H}\right.$, $\left.\mathrm{H}^{7 \mathrm{~A}}\right), 6.72\left(\mathrm{ddd},{ }^{3} J_{\mathrm{HH}}=7 \mathrm{~Hz}, 6 \mathrm{~Hz},{ }^{4} J_{\mathrm{HH}}=1 \mathrm{~Hz}, 2 \mathrm{H}, \mathrm{H}^{7 \mathrm{~B}}\right) .{ }^{13} \mathrm{C}$ $\left\{{ }^{1} \mathrm{H}\right\} \mathrm{NMR}\left(\mathrm{CD}_{3} \mathrm{CN}\right): \delta[\mathrm{ppm}]=233.3\left(\mathrm{C}^{9 \mathrm{~B}}\right), 169.4\left(\mathrm{C}^{10}\right), 168.9$ $\left(\mathrm{C}^{4 \mathrm{~B}}\right), 159.8\left(\mathrm{C}^{4 \mathrm{~A}}\right), 155.5\left(\mathrm{C}^{8 \mathrm{~A}}\right), 153.5\left(\mathrm{C}^{3 \mathrm{~A}}\right), 152.8\left(\mathrm{C}^{8 \mathrm{~B}}\right), 143.2$ $\left(\mathrm{C}^{3 \mathrm{~B}}\right), 136.7\left(\mathrm{C}^{6 \mathrm{~B}}\right), 136.4\left(\mathrm{C}^{6 \mathrm{~A}}\right), 133.9\left(\mathrm{C}^{1 \mathrm{~A}}\right), 127.4\left(\mathrm{C}^{7 \mathrm{~A}}\right), 125.0$ $\left(\mathrm{C}^{2 \mathrm{~B}}\right), 124.6\left(\mathrm{C}^{5 \mathrm{~A}}\right), 123.4\left(\mathrm{C}^{2 \mathrm{~A}}\right), 123.1\left(\mathrm{C}^{7 \mathrm{~B}}\right), 122.4\left(\mathrm{C}^{1 \mathrm{~B}}\right), 121.0$ $\left(\mathrm{C}^{5 \mathrm{~B}}\right)$. IR (KBr disk): $\tilde{\nu}\left[\mathrm{cm}^{-1}\right]=3440(\mathrm{~s}, \mathrm{O}-\mathrm{H}$ acid), $1665(\mathrm{~s}$, $\mathrm{C}=\mathrm{O}$ acid), 1602, 1579 (m, $\mathrm{C}=\mathrm{C}), 843$ (s, P-F).

Synthesis of $\left[\mathbf{R u}(\mathbf{d p b}-\mathrm{COOBt})\left(\mathrm{tpy}_{\mathbf{1}}\right)\right]\left(\mathbf{P F}_{\mathbf{6}}\right) \mathbf{5}\left(\mathbf{P F}_{\mathbf{6}}\right) \cdot[\mathrm{Ru}(\mathrm{dpb}-$ $\left.\left.\mathrm{COOC}_{2} \mathrm{H}_{5}\right)(\mathrm{tpy})\right]\left(\mathrm{PF}_{6}\right)$ 4( $\left.\mathrm{PF}_{6}\right)$ (42 mg, $0.056 \mathrm{mmol}, 1$ eq.), $N, N^{\prime}-$ diisopropylcarbodiimide (15 $\mathrm{mg}, 0.119 \mathrm{mmol}, 2.1 \mathrm{eq}$.$) and$ $N$-hydroxybenzotriazole (HOBt, $18 \mathrm{mg}, 0.117 \mathrm{mmol}, 2.1 \mathrm{eq}$. were dissolved in dry acetonitrile $(20 \mathrm{ml})$ and stirred for $16 \mathrm{~h}$ at room temperature. After removal of the solvent under reduced pressure, the dark residue was dissolved in acetonitrile $(5 \mathrm{ml})$. The product was precipitated by addition of $\mathrm{NH}_{4} \mathrm{PF}_{6}$ (95 mg, $0.583 \mathrm{mmol}, 10.4$ eq.) and water (50 ml), filtered off and washed with water $(2 \times 5 \mathrm{ml})$ and diethyl ether $(2 \times 15 \mathrm{ml})$. [Ru(dpb-COOBt $)(\mathrm{tpy})]\left(\mathrm{PF}_{6}\right) \mathbf{5}\left(\mathrm{PF}_{6}\right)$ was obtained as a dark red solid. Yield: $45 \mathrm{mg}(0.052 \mathrm{mmol}, 92 \%)$. Anal. Calc. for $\mathrm{C}_{38} \mathrm{H}_{25} \mathrm{~F}_{6} \mathrm{~N}_{8} \mathrm{O}_{2} \mathrm{PRu}$ (871.69): C, 52.36; H, 2.89; N, 12.85 . 
Found: C, 52.42; H, 2.53; N, 12.54. $\mathrm{MS}\left(\mathrm{ESI}^{+}\right): \mathrm{m} / \mathrm{z}(\%)=699.1$ (11) $\left[\mathrm{M}-\mathrm{PF}_{6}-\mathrm{N}_{2}\right]^{+}, 727.1(100)\left[\mathrm{M}-\mathrm{PF}_{6}\right]^{+}, 1599.2$ (8) $[2 \mathrm{M}-$ $\left.\mathrm{PF}_{6}\right]^{+}$. HR-MS(ESI $\left.{ }^{+}, \mathrm{m} / \mathrm{z}\right)$ : Calcd for $\mathrm{C}_{38} \mathrm{H}_{25} \mathrm{~N}_{8} \mathrm{O}_{2} \mathrm{Ru}\left[\mathrm{M}-\mathrm{PF}_{6}\right]^{+}$: 721.1176; Found: 721.1192. ${ }^{1} \mathrm{H}$ NMR $\left(\mathrm{CD}_{3} \mathrm{CN}\right): \delta[\mathrm{ppm}]=9.05$ $\left(\mathrm{s}, 2 \mathrm{H}, \mathrm{H}^{2 \mathrm{~B}}\right), 8.77\left(\mathrm{~d}, 2 \mathrm{H},{ }^{3} J_{\mathrm{HH}}=8 \mathrm{~Hz}, \mathrm{H}^{2 \mathrm{~A}}\right), 8.44\left(\mathrm{~d}, 2 \mathrm{H},{ }^{3} J_{\mathrm{HH}}=\right.$ $\left.8 \mathrm{~Hz}, \mathrm{H}^{5 \mathrm{~A}}\right), 8.35\left(\mathrm{t}, 1 \mathrm{H},{ }^{3} J_{\mathrm{HH}}=8 \mathrm{~Hz}, \mathrm{H}^{1 \mathrm{~A}}\right), 8.34\left(\mathrm{~d}, 2 \mathrm{H},{ }^{3} J_{\mathrm{HH}}=\right.$ $\left.8 \mathrm{~Hz}, \mathrm{H}^{5 \mathrm{~B}}\right), 8.16\left(\mathrm{~d}, 1 \mathrm{H},{ }^{3} J_{\mathrm{HH}}=9 \mathrm{~Hz}, \mathrm{H}^{2 \mathrm{C}}\right), 7.83\left(\mathrm{~d}, 1 \mathrm{H},{ }^{3} J_{\mathrm{HH}}=\right.$ $\left.8 \mathrm{~Hz}, \mathrm{H}^{5 \mathrm{C}}\right), 7.77-7.66\left(\mathrm{~m}, 5 \mathrm{H}, \mathrm{H}^{6 \mathrm{~A}}, \mathrm{H}^{6 \mathrm{~B}}, \mathrm{H}^{4 \mathrm{C}}\right), 7.58\left(\mathrm{t}, 1 \mathrm{H}, \mathrm{H}^{3 \mathrm{C}}\right)$, $7.20\left(\mathrm{~d}, 2 \mathrm{H},{ }^{3} J_{\mathrm{HH}}=5 \mathrm{~Hz}, \mathrm{H}^{8 \mathrm{~B}}\right), 7.13\left(\mathrm{~d}, 2 \mathrm{H},{ }^{3} J_{\mathrm{HH}}=5 \mathrm{~Hz}, \mathrm{H}^{8 \mathrm{~A}}\right)$, $6.96\left(\mathrm{t}, 2 \mathrm{H},{ }^{3} J_{\mathrm{HH}}=6 \mathrm{~Hz}, \mathrm{H}^{7 \mathrm{~A}}\right), 6.80\left(\mathrm{t}, 2 \mathrm{H},{ }^{3} \mathrm{~J}_{\mathrm{HH}}=6 \mathrm{~Hz}, \mathrm{H}^{7 \mathrm{~B}}\right) .{ }^{13} \mathrm{C}$ $\left\{{ }^{1} \mathrm{H}\right\} \operatorname{NMR}\left(\mathrm{CD}_{3} \mathrm{CN}\right): \delta[\mathrm{ppm}]=239.5\left(\mathrm{C}^{9 \mathrm{~B}}\right), 168.2\left(\mathrm{C}^{4 \mathrm{~B}}\right), 165.7$ $\left(\mathrm{C}^{10}\right), 159.7\left(\mathrm{C}^{4 \mathrm{~A}}\right), 155.5\left(\mathrm{C}^{8 \mathrm{~A}}\right), 153.3\left(\mathrm{C}^{3 \mathrm{~A}}\right), 152.9\left(\mathrm{C}^{8 \mathrm{~B}}\right), 144.5$ $\left(\mathrm{C}^{1 \mathrm{C}}\right), 144.2\left(\mathrm{C}^{3 \mathrm{~B}}\right), 137.0\left(\mathrm{C}^{6 \mathrm{~B}}\right), 136.9\left(\mathrm{C}^{6 \mathrm{~A}}\right), 134.8\left(\mathrm{C}^{1 \mathrm{~A}}\right), 130.1$ $\left(\mathrm{C}^{4 \mathrm{C}}\right), 127.5\left(\mathrm{C}^{7 \mathrm{~A}}\right), 126.2\left(\mathrm{C}^{3 \mathrm{C}}\right), 124.9\left(\mathrm{C}^{2 \mathrm{~B}}\right), 124.8\left(\mathrm{C}^{5 \mathrm{~A}}\right), 123.6$ $\left(\mathrm{C}^{7 \mathrm{~B}}\right), 123.5\left(\mathrm{C}^{2 \mathrm{~A}}\right), 121.3\left(\mathrm{C}^{2 \mathrm{C}}\right), 121.1\left(\mathrm{C}^{6 \mathrm{C}}\right), 115.4\left(\mathrm{C}^{1 \mathrm{~B}}\right), 110.0$ $\left(\mathrm{C}^{5 \mathrm{C}}\right)$.

Synthesis of $[(t p y) R u(d p b-N H C O-d p b) R u(t p y)]\left(P_{6}\right)_{2} \quad 6\left(P_{6}\right)_{2}$. In separate Schlenk flasks, $\left[\mathrm{Ru}\left(\mathrm{dpb}-\mathrm{NH}_{2}\right)(\mathrm{tpy})\right]\left(\mathrm{PF}_{6}\right) \quad 2\left(\mathrm{PF}_{6}\right)$ (35 mg, $0.048 \mathrm{mmol}, 1$ eq.) and $[\mathrm{Ru}(\mathrm{dpb}-\mathrm{COOBt})(\mathrm{tpy})]\left(\mathrm{PF}_{6}\right)$ 5( $\left.\mathrm{PF}_{6}\right)$ (42 mg, $0.048 \mathrm{mmol}, 1$ eq.) were dissolved in dry acetonitrile $(10 \mathrm{ml})$. Molecular sieves $(3 \AA)$ were added and the mixtures were left to stand overnight to remove crystal water. Both solutions were then combined in a third Schlenk flask and tert-butylimino-tris(dimethylamino)phosphorane $\left(\mathrm{P}_{1}-t \mathrm{Bu}\right)$ (34 mg, $0.144 \mathrm{mmol}, 3$ eq.) was added. The resulting solution was stirred at $50{ }^{\circ} \mathrm{C}$ for $16 \mathrm{~h}$. After quenching the reaction by addition of $\mathrm{NH}_{4} \mathrm{PF}_{6}(180 \mathrm{mg}, 1.10 \mathrm{mmol}, 23$ eq.) dissolved in water $(2 \mathrm{ml})$, the solution was concentrated to $5 \mathrm{ml}$ and the product was triturated by addition of water $(80 \mathrm{ml})$. The precipitate was filtered off, washed with water $(2 \times 5 \mathrm{ml})$ and diethyl ether $(2 \times 15 \mathrm{ml})$ and purified by column chromatography on silica gel $\left(\mathrm{CHCl}_{3}: \mathrm{MeOH}=7: 1\right)$ affording [(tpy) $\mathrm{Ru}(\mathrm{dpb}-\mathrm{NHCO}-\mathrm{dpb}) \mathrm{Ru}(\mathrm{tpy})]\left(\mathrm{PF}_{6}\right)_{2} \mathbf{6}\left(\mathrm{PF}_{6}\right)_{2}$ as a dark red solid. Yield: $14 \mathrm{mg}(0.0096 \mathrm{mmol}, 20 \%)$. Anal. Calc. for $\mathrm{C}_{63} \mathrm{H}_{43} \mathrm{~F}_{12} \mathrm{~N}_{11} \mathrm{OP}_{2} \mathrm{Ru}_{2}$ (1462.16) $4 \mathrm{H}_{2} \mathrm{O}: \mathrm{C}, 49.32 ; \mathrm{H}, 3.35 ; \mathrm{N}$,

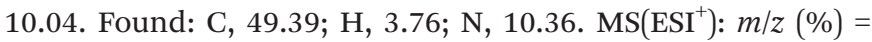
$296.6(3)\left[\mathrm{M}-2 \mathrm{PF}_{6}\right]^{4+}, 390.8$ (17) $\left[\mathrm{M}-2 \mathrm{PF}_{6}\right]^{3+}, 586.6$ (100) $\left[\mathrm{M}-2 \mathrm{PF}_{6}\right]^{2+}, 1318.3(5)\left[\mathrm{M}-\mathrm{PF}_{6}\right]^{+}$. HR-MS(ESI $\left.{ }^{+}, \mathrm{m} / \mathrm{z}\right)$ : Calcd for $\mathrm{C}_{63} \mathrm{H}_{43} \mathrm{~N}_{11} \mathrm{ORu}_{2}\left[\mathrm{M}-2 \mathrm{PF}_{6}\right]^{2+}$ : 586.5885; Found: 586.5884 . ${ }^{1} \mathrm{H}$ NMR $\left(\mathrm{CD}_{3} \mathrm{CN}\right): \delta[\mathrm{ppm}]=9.63(\mathrm{~s}, 1 \mathrm{H}, \mathrm{NH}), 9.09(\mathrm{~s}, 2 \mathrm{H}$, $\left.\mathrm{H}^{2 \mathrm{~A}}\right), 8.83\left(\mathrm{~s}, 2 \mathrm{H}, \mathrm{H}^{2 \mathrm{~B}}\right), 8.80-8.74\left(\mathrm{~m}, 4 \mathrm{H}, \mathrm{H}^{2, \text { tpy }}\right), 8.44(\mathrm{~m}, 4 \mathrm{H}$, $\left.\mathrm{H}^{5, \text { tpy }}\right), 8.39\left(\mathrm{~d},{ }^{3} J_{\mathrm{HH}}=8 \mathrm{~Hz}, 2 \mathrm{H}, \mathrm{H}^{5 \mathrm{~A}}\right), 8.32\left(\mathrm{t},{ }^{3} J_{\mathrm{HH}}=8 \mathrm{~Hz}, 1 \mathrm{H}\right.$, $\left.\mathrm{H}^{1, \text { tpy }}\right), 8.28\left(\mathrm{t},{ }^{3} J_{\mathrm{HH}}=8 \mathrm{~Hz}, 1 \mathrm{H}, \mathrm{H}^{1, \mathrm{tpy}}\right), 8.18\left(\mathrm{~d},{ }^{3} J_{\mathrm{HH}}=8 \mathrm{~Hz}\right.$, $\left.2 \mathrm{H}, \mathrm{H}^{5 \mathrm{~B}}\right), 7.76-7.65\left(\mathrm{~m}, 6 \mathrm{H}, \mathrm{H}^{6, \text { tpy }}, \mathrm{H}^{6 \mathrm{~A}}\right), 7.65-7.59(\mathrm{~m}, 2 \mathrm{H}$, $\left.\mathrm{H}^{6 \mathrm{~B}}\right), 7.19-7.10\left(\mathrm{~m}, 6 \mathrm{H}, \mathrm{H}^{8, \text { tpy }}, \mathrm{H}^{8 \mathrm{~A}}\right), 7.07\left(\mathrm{~d},{ }^{3} J_{\mathrm{HH}}=6 \mathrm{~Hz}, 2 \mathrm{H}\right.$, $\left.\mathrm{H}^{8 \mathrm{~B}}\right), 6.96-6.88\left(\mathrm{~m}, \mathrm{br}, 4 \mathrm{H}, \mathrm{H}^{7, \mathrm{tpy}}\right), 6.75\left(\mathrm{~m}, 2 \mathrm{H}, \mathrm{H}^{7 \mathrm{~A}}\right), 6.68$ $\left(\mathrm{m}, 2 \mathrm{H}, \mathrm{H}^{7 \mathrm{~B}}\right) .{ }^{13} \mathrm{C}\left\{{ }^{1} \mathrm{H}\right\} \mathrm{NMR}\left(\mathrm{CD}_{3} \mathrm{CN}\right): \delta[\mathrm{ppm}]=230.3\left(\mathrm{C}^{9 \mathrm{~A}}\right)$, $217.9\left(\mathrm{C}^{9 \mathrm{~B}}\right), 169.6\left(\mathrm{C}^{5 \mathrm{~B}}\right), 169.3\left(\mathrm{C}^{5 \mathrm{~A}}\right), 168.0\left(\mathrm{C}^{10}\right), 160.2,160.0$ $\left(\mathrm{C}^{4, \text { tpy }}\right), 155.3,155.2\left(\mathrm{C}^{8, \text { tpy }}\right), 154.0,153.6\left(\mathrm{C}^{3, \text { tpy }}\right), 153.0\left(\mathrm{C}^{8 \mathrm{~A}}\right.$, $\left.\mathrm{C}^{8 \mathrm{~B}}\right), 143.2\left(\mathrm{C}^{3 \mathrm{~A}}\right), 142.7\left(\mathrm{C}^{3 \mathrm{~B}}\right), 136.8,136.5,136.4,136.0\left(\mathrm{C}^{6, \mathrm{tpy}}\right.$, $\left.\mathrm{C}^{6 \mathrm{~A}}, \mathrm{C}^{6 \mathrm{~B}}\right), 133.9\left(\mathrm{C}^{1 \mathrm{~B}}\right), 133.8,132.9\left(\mathrm{C}^{1, \text { tpy }}\right), 127.9\left(\mathrm{C}^{1 \mathrm{~A}}\right), 127.3$ $\left(\mathrm{C}^{7, \text { tpy }}\right), 124.6,124.4\left(\mathrm{C}^{5, \text { tpy }}\right), 123.4,123.3\left(\mathrm{C}^{2, \text { tpy }}\right), 123.3\left(\mathrm{C}^{2 \mathrm{~A}}\right)$, $123.0\left(\mathrm{C}^{7 \mathrm{~A}}\right), 122.6\left(\mathrm{C}^{7 \mathrm{~B}}\right), 120.9\left(\mathrm{C}^{8 \mathrm{~A}}\right), 120.7\left(\mathrm{C}^{8 \mathrm{~B}}\right), 118.9\left(\mathrm{C}^{2 \mathrm{~B}}\right)$. IR $\left(\mathrm{KBr}\right.$ disk): $\tilde{\nu}\left[\mathrm{cm}^{-1}\right]=3220(\mathrm{~m}, \mathrm{~N}-\mathrm{H}$ amide $), 1635(\mathrm{~s}$, $\mathrm{C}=\mathrm{O}$ amide), 1599, $1582(\mathrm{~m}, \mathrm{C}=\mathrm{C}), 1517$ (w, amide II), 843 (s, $\mathrm{P}-\mathrm{F})$.

\section{Conclusions}

The electrochemical, UV-Vis and excited state properties of a series of $[\mathrm{Ru}(\mathrm{dpb}-\mathrm{R})(\mathrm{tpy})]^{+}$type of complexes was systematically studied. The visible range absorption bands of these complexes are dominated by two electronically decoupled ${ }^{1}$ MLCT transitions either involving the dpb ligand $\left(d_{y z}(R u) \rightarrow d p b\right)$ or the tpy ligand $\left(d_{x z}(R u) \rightarrow\right.$ tpy). These excitations are followed by intersystem crossing populating an emissive $\left[\mathrm{Ru}^{+}\left(\mathrm{tpy}^{-}\right)\right]$ ${ }^{3}$ MLCT state in all cases. This state, however, is rapidly depopulated at room temperature via two additional lowenergy triplet excited states yielding very low luminescence quantum yields and short excited state lifetimes. VT steadystate emission spectroscopy and extended DFT calculations revealed their nature as ${ }^{3} \mathrm{LL}$ 'CT and ${ }^{3} \mathrm{MC}$ states yielding a biexponential dependence of the quantum yield on the temperature. While the ${ }^{3} \mathrm{MC}$ state has been known as a parasitic channel for non-radiative decay in (polypyridine)ruthenium(II) complexes for over 30 years, ${ }^{22}$ the observation of a ${ }^{3} \mathrm{LL}$ 'CT state in such ruthenium complexes is unprecedented to the best of our knowledge. We previously referred to the ${ }^{3} \mathrm{LL}$ CT state as a spectroscopically undetectable state ("dark" state). ${ }^{40}$ However, the characteristic temperature dependence of the quantum yield clearly is spectroscopic evidence for its presence. Also for the bis(tridentate)iridium(III) complex $[\operatorname{Ir}(\mathrm{dpx})(\mathrm{tpy})]^{2+}(\mathrm{dpxH}=$ 1,5-di(2-pyridyl)-2,4-xylene), a ${ }^{3}$ LL'CT state is suggested to be responsible for its low luminescence quantum yield. ${ }^{101}$ Based upon the findings of this study, we believe that the excited state deactivation in this cyclometalated iridium complex occurs in an analogous manner via thermal depopulation of the emissive state via ${ }^{3} \mathrm{LL}$ 'CT states.

Remarkably, for the acceptor-substituted complexes $3^{+}$and $4^{+}$, the ${ }^{3}$ LL'CT state resides higher in energy than the ${ }^{3}$ MLCT state, while for the donor-substituted complexes $\mathbf{1}^{+}$and $2^{+}$, it is found to be the lowest triplet state. As a consequence, faster deactivation of the emissive ${ }^{3}$ MLCT states is observed in the latter complexes associated with substantially lowered emission quantum yields compared to complexes $3^{+}$and $4^{+}$. But, since emission is observed for $\mathbf{1}^{+}$and $2^{+}$with increasing quantum yields at lower temperatures, deactivation via the ${ }^{3} \mathrm{LL}$ 'CT state is a thermally activated process and the ${ }^{3} \mathrm{MLCT}$ and ${ }^{3}$ LL'CT states are not in thermal equilibrium.

Upon oxidation of the dinuclear complex $6^{2+}$ to its mixedvalent counterpart $6^{3+}$, an intense NIR band is detected indicating a photochemical $\mathrm{Ru}^{\mathrm{II}} \rightarrow \mathrm{Ru}^{\mathrm{III}}$ charge transfer across the asymmetric biscyclometalating bridging ligand. Despite the substantial redox asymmetry of the two complex subunits bearing $\mathrm{NH}$ - and CO-substituents, a strong electronic communication between the donor and acceptor sites of $6^{3+}$ is observed. In the excited state of $6^{2+}$ however, the two complex fragments appear electronically uncoupled with dual emission occurring from ${ }^{3}$ MLCT states localized at the two remote $[\mathrm{Ru}(\mathrm{tpy})]$ moieties. This "anti-Kasha" behaviour is explained based on the long metal-metal distance and the very rapid excited state decay (emissive and non-emissive) that prevents thermal equilibration in solution via energy transfer entirely. 
Just upon freezing of the solution, the excited states become sufficiently long-lived to allow for thermalization, so that Kasha's rule is obeyed.

In summary, we were able to show spectroscopically and computationally that the introduction of $\mathrm{N}^{\wedge} \mathrm{C}^{\wedge} \mathrm{N}$ cyclometalating ligands in bis(tridentate)ruthenium(II) complexes gives rise to low-lying ${ }^{3} \mathrm{LL}$ 'CT states that allow for efficient thermal depopulation of the emissive ${ }^{3}$ MLCT state. Furthermore, we believe that the existence of ${ }^{3} \mathrm{LL}^{\prime} \mathrm{CT}$ states in polypyridine transition metal complexes is more general. As their energy is strongly dependent on the substitution pattern, they become particularly relevant in strong push-pull systems and can interfere with luminescence processes and shorten the excited state lifetimes substantially.

Additionally, in mixed-valent dinuclear ruthenium complexes such as $6^{3+}$, the biscyclometalating bridge was shown to be an excellent mediator for photochemical electron transfer between the redox sites even in the presence of a substantial redox asymmetry. The triplet excited states of $6^{2+}$, however, are electronically uncoupled due to the large spatial separation of the emissive $[\mathrm{Ru}(\mathrm{tpy})]$ moieties and their short excited state lifetimes induced by the cyclometalating bridge.

\section{Acknowledgements}

Parts of this research were conducted using the supercomputer MOGON and advisory services offered by Johannes Gutenberg Univ. Mainz (http://www.hpc.uni-mainz.de), which is a member of the AHRP and the Gauss Alliance e.V. This work was financially supported by the Deutsche Forschungsgemeinschaft (GSC 266, Materials Science in Mainz, scholarship for C. K.).

\section{Notes and references}

1 J. P. Paris and W. W. Brandt, J. Am. Chem. Soc., 1959, 81, 5001-5002.

2 F. E. Lytle and D. M. Hercules, J. Am. Chem. Soc., 1969, 91, 253-257.

3 K. Kalyanasundaram, Coord. Chem. Rev., 1982, 46, 159244.

4 A. Juris, V. Balzani, F. Barigelletti, S. Campagna, P. Belser and A. von Zelewsky, Coord. Chem. Rev., 1988, 84, 85-277.

5 M. Maestri, N. Armaroli, V. Balzani, E. C. Constable and A. M. W. C. Thompson, Inorg. Chem., 1995, 34, 2759-2767.

6 V. Balzani and A. Juris, Coord. Chem. Rev., 2001, 211, 97-115.

7 S. Campagna, F. Puntoriero, F. Nastasi, G. Bergamini and V. Balzani, Top. Curr. Chem., 2007, 280, 117-214.

8 D. M. Hedstrand, W. H. Kruizinga and R. M. Kellogg, Tetrahedron Lett., 1978, 19, 1255-1258.

9 H. D. Abruna, A. Y. Teng, G. J. Samuels and T. J. Meyer, J. Am. Chem. Soc., 1979, 101, 6745-6746.
10 I. Okura and N. Kim-Thuan, J. Mol. Catal., 1979, 5, 311314.

11 J.-M. Lehn and R. Ziessel, Proc. Natl. Acad. Sci. U. S. A., 1982, 79, 701-704.

12 J. W. Tucker and C. R. J. Stephenson, J. Org. Chem., 2012, 77, 1617-1622.

13 B. O’Regan and M. Grätzel, Nature, 1991, 353, 737740.

14 M. G. Sasso, F. H. Quina and E. J. Bechara, Anal. Biochem., 1986, 156, 239-243.

15 K. K.-W. Lo, T. K.-M. Lee, J. S.-Y. Lau, W.-L. Poon and S.-H. Cheng, Inorg. Chem., 2008, 47, 200-208.

16 P. D. Beer, Z. Chen, A. J. Goulden, A. Grieve, D. Hesek, F. Szemes and T. Wear, J. Chem. Soc., Chem. Commun., 1994, 1269-1271.

17 H. J. Bolink, L. Cappelli, E. Coronado and P. Gaviña, Inorg. Chem., 2005, 44, 5966-5968.

18 J. N. Demas and D. G. Taylor, Inorg. Chem., 1979, 18, 3177-3179.

19 S. Yoon, P. Kukura, C. M. Stuart and R. A. Mathies, Mol. Phys., 2006, 104, 1275-1282.

20 J. V. Caspar and T. J. Meyer, J. Am. Chem. Soc., 1983, 105, 5583-5590.

21 K. Suzuki, A. Kobayashi, S. Kaneko, K. Takehira, T. Yoshihara, H. Ishida, Y. Shiina, S. Oishi and S. Tobita, Phys. Chem. Chem. Phys., 2009, 11, 9850-9860.

22 B. Durham, J. V. Caspar, J. K. Nagle and T. J. Meyer, J. Am. Chem. Soc., 1982, 104, 4803-4810.

23 J. van Houten and R. J. Watts, Inorg. Chem., 1978, 17, 3381-3385.

24 J. P. Sauvage, J. P. Collin, J. C. Chambron, S. Guillerez, C. Coudret, V. Balzani, F. Barigelletti, L. de Cola and L. Flamigni, Chem. Rev., 1994, 94, 993-1019.

25 K. Lashgari, M. Kritikos, R. Norrestam and T. Norrby, Acta Crystallogr., Sect. C: Cryst. Struct. Commun., 1999, 55, 64-67.

26 J. R. Winkler, T. L. Netzel, C. Creutz and N. Sutin, J. Am. Chem. Soc., 1987, 109, 2381-2392.

27 M. L. Stone and G. A. Crosby, Chem. Phys. Lett., 1981, 79, 169-173.

28 K. Heinze, K. Hempel and M. Beckmann, Eur. J. Inorg. Chem., 2006, 2006, 2040-2050.

29 K. Heinze, K. Hempel and A. Breivogel, Z. Anorg. Allg. Chem., 2009, 635, 2541-2549.

30 S. H. Wadman, M. Lutz, D. M. Tooke, A. L. Spek, F. Hartl, R. W. A. Havenith, G. P. M. van Klink and G. van Koten, Inorg. Chem., 2009, 48, 1887-1900.

31 A. Breivogel, C. Kreitner and K. Heinze, Eur. J. Inorg. Chem., 2014, 2014, 5468-5490.

32 M. Abrahamsson, M. Jäger, T. Österman, L. Eriksson, P. Persson, H.-C. Becker, O. Johansson and L. Hammarström, J. Am. Chem. Soc., 2006, 128, 1261612617.

33 F. Schramm, V. Meded, H. Fliegl, K. Fink, O. Fuhr, Z. Qu, W. Klopper, S. Finn, T. E. Keyes and M. Ruben, Inorg. Chem., 2009, 48, 5677-5684. 
34 A. Breivogel, C. Förster and K. Heinze, Inorg. Chem., 2010, 49, 7052-7056.

35 A. Breivogel, M. Meister, C. Förster, F. Laquai and K. Heinze, Chem. - Eur. J., 2013, 19, 13745-13760.

36 D. G. Brown, N. Sanguantrakun, B. Schulze, U. S. Schubert and C. P. Berlinguette, J. Am. Chem. Soc., 2012, 134, 12354-12357.

37 M. Beley, J. P. Collin and J. P. Sauvage, Inorg. Chem., 1993, 32, 4539-4543.

38 S. H. Wadman, J. M. Kroon, K. Bakker, M. Lutz, A. L. Spek, G. P. M. van Klink and G. van Koten, Chem. Commun., 2007, 1907-1909.

39 P. G. Bomben, K. C. D. Robson, P. A. Sedach and C. P. Berlinguette, Inorg. Chem., 2009, 48, 96319643.

40 C. Kreitner, E. Erdmann, W. W. Seidel and K. Heinze, Inorg. Chem., 2015, 54, 11088-11104.

41 C. Creutz and H. Taube, J. Am. Chem. Soc., 1969, 91, 39883989.

42 W. Kaim, A. Klein and M. Glöckle, Acc. Chem. Res., 2000, 33, 755-763.

43 W. Kaim and G. K. Lahiri, Angew. Chem., 2007, 119, 18081828, (Angew. Chem., Int. Ed., 2007, 46, 1778-1796).

44 U. Fuerholz, H. B. Buergi, F. E. Wagner, A. Stebler, J. H. Ammeter, E. Krausz, R. J. H. Clark, M. J. Stead and A. Ludi, J. Am. Chem. Soc., 1984, 106, 121-123.

45 L. T. Zhang, J. Ko and M. J. Ondrechen, J. Am. Chem. Soc., 1987, 109, 1666-1671.

46 S. P. Best, R. J. H. Clark, R. C. S. McQueen and S. Joss, J. Am. Chem. Soc., 1989, 111, 548-550.

47 B. S. Brunschwig, C. Creutz and N. Sutin, Chem. Soc. Rev., 2002, 31, 168-184.

48 M. B. Robin and P. Day, Adv. Inorg. Chem., 1968, 10, 247422.

49 N. S. Hush, Prog. Inorg. Chem., 1967, 8, 391-444.

50 N. S. Hush, Electrochim. Acta, 1968, 13, 1005-1023.

51 N. S. Hush, Coord. Chem. Rev., 1985, 64, 135-157.

52 B. S. Brunschwig and N. Sutin, Coord. Chem. Rev., 1999, 187, 233-254.

53 G. D. Storrier and S. B. Colbran, Inorg. Chim. Acta, 1999, 284, 76-84.

54 A. Breivogel, K. Hempel and K. Heinze, Inorg. Chim. Acta, 2011, 374, 152-162.

55 C. Kreitner, M. Grabolle, U. Resch-Genger and K. Heinze, Inorg. Chem., 2014, 53, 12947-12961.

56 E. C. Constable and M. D. Ward, J. Chem. Soc., Dalton Trans., 1990, 1405-1409.

57 J.-P. Collin, P. Lainé, J.-P. Launay, J.-P. Sauvage and A. Sour, J. Chem. Soc., Chem. Commun., 1993, 434-435.

58 M. Beley, J. P. Collin, R. Louis, B. Metz and J. P. Sauvage, J. Am. Chem. Soc., 1991, 113, 8521-8522.

59 C. Patoux, J.-P. Launay, M. Beley, S. Chodorowski-Kimmes, J.-P. Collin, S. James and J.-P. Sauvage, J. Am. Chem. Soc., 1998, 120, 3717-3725.

60 J.-Y. Shao and Y.-W. Zhong, Chem. - Eur. J., 2014, 20, 8702-8713.
61 K. C. D. Robson, B. D. Koivisto, A. Yella, B. Sporinova, M. K. Nazeeruddin, T. Baumgartner, M. Grätzel and C. P. Berlinguette, Inorg. Chem., 2011, 50, 5494-5508.

62 W. König and R. Geiger, Chem. Ber., 1970, 103, 788798.

63 A. D. Becke, J. Chem. Phys., 1993, 98, 5648-5652.

64 A. Schäfer, H. Horn and R. Ahlrichs, J. Chem. Phys., 1992, 97, 2571-2577.

65 A. Schäfer, C. Huber and R. Ahlrichs, J. Chem. Phys., 1994, 100, 5829-5835.

66 F. Weigend and R. Ahlrichs, Phys. Chem. Chem. Phys, 2005, 7, 3297-3305.

67 E. van Lenthe, E. J. Baerends and J. G. Snijders, J. Chem. Phys., 1993, 99, 4597-4610.

68 S. Sinnecker, A. Rajendran, A. Klamt, M. Diedenhofen and F. Neese, J. Phys. Chem. A, 2006, 110, 2235-2245.

69 M. C. Hughes and D. J. Macero, Inorg. Chem., 1976, 15, 2040-2044.

70 S. Romain, C. Baffert, C. Duboc, J.-C. Leprêtre, A. Deronzier and M.-N. Collomb, Inorg. Chem., 2009, 48, 3125-3131.

71 R. F. Winter, Organometallics, 2014, 33, 4517-4536.

72 N. G. Connelly and W. E. Geiger, Chem. Rev., 1996, 96, 877-910.

73 C. Creutz, M. D. Newton and N. Sutin, J. Photochem. Photobiol., A, 1994, 82, 47-59.

74 J.-P. Launay, Chem. Soc. Rev., 2001, 30, 386-397.

75 L. Wang, W.-W. Yang, R.-H. Zheng, Q. Shi, Y.-W. Zhong and J. Yao, Inorg. Chem., 2011, 50, 7074-7079.

76 W.-W. Yang, L. Wang, Y.-W. Zhong and J. Yao, Organometallics, 2011, 30, 2236-2240.

77 D. E. Richardson and H. Taube, J. Am. Chem. Soc., 1983, 105, 40-51.

78 M. Natali, S. Campagna and F. Scandola, Chem. Soc. Rev., 2014, 43, 4005-4018.

79 F. Barigelletti, A. Juris, V. Balzani, P. Belser and A. von Zelewsky, Inorg. Chem., 1983, 22, 3335-3339.

80 A. Juris, F. Barigelletti, V. Balzani, P. Belser and A. von Zelewsky, Inorg. Chem., 1985, 24, 202-206.

81 G. A. Crosby, Acc. Chem. Res., 1975, 8, 231-238.

82 F. Barigelletti, A. Juris, V. Balzani, P. Belser and A. von Zelewsky, J. Phys. Chem., 1986, 90, 5190-5193.

83 R. Englman and J. Jortner, Mol. Phys., 1970, 18, 145164.

84 J. V. Caspar, E. M. Kober, B. P. Sullivan and T. J. Meyer, J. Am. Chem. Soc., 1982, 104, 630-632.

85 J. V. Caspar and T. J. Meyer, J. Phys. Chem., 1983, 87, 952957.

86 K. A. King and R. J. Watts, J. Am. Chem. Soc., 1987, 109, 1589-1590.

87 T. E. Keyes, Chem. Commun., 1998, 889-890.

88 E. C. Glazer, D. Magde and Y. Tor, J. Am. Chem. Soc., 2007, 129, 8544-8551.

89 Y. Chen, X. Zhou, X.-H. Wei, B.-L. Yu, H. Chao and L.-N. Ji, Inorg. Chem. Commun., 2010, 13, 1018-1020.

90 D. L. Dexter, J. Chem. Phys., 1953, 21, 836-850. 
91 F. Barigelletti, L. Flamigni, V. Balzani, J.-P. Collin, J.-P. Sauvage, A. Sour, E. C. Constable and A. M. W. C. Thompson, J. Am. Chem. Soc., 1994, 116, 7692-7699.

92 V. Grosshenny, A. Harriman and R. Ziessel, Angew. Chem., 1995, 107, 1211-1214, (Angew. Chem. Int. Ed., 1995, 34, 1100-1102).

93 B. Schlicke, P. Belser, L. de Cola, E. Sabbioni and V. Balzani, J. Am. Chem. Soc., 1999, 121, 42074214.

94 M. Kasha, Discuss. Faraday Soc., 1950, 9, 14-19.

95 B. P. Sullivan, J. M. Calvert and T. J. Meyer, Inorg. Chem., 1980, 19, 1404-1407.
96 G. R. Fulmer, A. J. M. Miller, N. H. Sherden, H. E. Gottlieb, A. Nudelman, B. M. Stoltz, J. E. Bercaw and K. I. Goldberg, Organometallics, 2010, 29, 2176-2179.

97 F. Neese, Wiley Interdiscip. Rev.: Comput. Mol. Sci., 2012, 2 , 73-78.

98 F. Neese, F. Wennmohs, A. Hansen and U. Becker, Chem. Phys., 2009, 356, 98-109.

99 R. Izsák and F. Neese, J. Chem. Phys., 2011, 135, 144105.

100 D. A. Pantazis, X.-Y. Chen, C. R. Landis and F. Neese, J. Chem. Theory Comput., 2008, 4, 908-919.

101 A. J. Wilkinson, H. Puschmann, J. A. K. Howard, C. E. Foster and J. A. G. Williams, Inorg. Chem., 2006, 45, 8685-8699. 